\title{
Estimating turbidity and total suspended matter in the Adour River plume (South Bay of Biscay) using MODIS 250-m imagery
}

\author{
Caroline Petus $^{\mathrm{a},{ }^{*}}$, Guillem Chust ${ }^{\mathrm{b}, 1}$, Francis Gohin ${ }^{\mathrm{c}, 2}$, David Doxaran ${ }^{\mathrm{d}, 3}$, Jean-Marie Froidefond ${ }^{\mathrm{a}}$ and \\ Yolanda Sagarminaga ${ }^{b}$
}

\footnotetext{
a Université Bordeaux 1, UMR EPOC 5805 CNRS, Avenue des Facultés, 33405 Talence Cedex, France

${ }^{\text {b }}$ AZTI-Tecnalia, Marine Research Division, Herrera Kaia Portualdea z/g, 20110 Pasaia, Spain

' IFREMER, Département Dynamiques de l'Environnement Côtier, DYNECO/PELAGOS, Ifremer Brest, BP 70, 29280 Plouzane Brittany, France

d Laboratoire d'Océanographie de Villefranche, UMR 7093-CNRS/UPMC, BP 8, 06238 Villefranche-sur-Mer

Cedex, France
}

\author{
*: Corresponding author : Caroline Petus, Tel.: +33 5400088 32; fax: +33 5568408 48, email address : \\ c.petus@epoc.u-bordeaux1.fr \\ ${ }^{1}$ Tel.: +34 943004800; fax: +34 943004801. \\ ${ }^{2}$ Tel.: +3329822 40 40; fax: +33298224548. \\ 3 Tel.: +33 4937637 18; fax: +3349376 3739 .
}

\begin{abstract}
:
The Basque coastal waters (South Bay of Biscay) are directly influenced by the Adour River freshwater plume. The Adour outflow leads to important variations of suspended matter concentrations and turbidity, which in turn may affect biological productivity and water quality. This study aims at both developing specific algorithms and testing the efficiency of atmospherically corrected MODIS-Aqua 250-m surface reflectance product (MYD09) to map total suspended matter concentrations and turbidity within the Adour coastal region. First, regional empirical algorithms based on in-situ data were tested to retrieve the concentration of total suspended matter and turbidity from the remote sensing reflectance. Then, the respective sensitivity of MODIS surface reflectance bands 1 and 2 for water quality application was investigated as well as the quality of atmospheric corrections. Finally, selected algorithms were applied to the MYD09 product. The resulting 250-m resolution maps were then compared to 1000-m maps produced by IFREMER and comparisons between satellite measurements and in-situ sampling points were performed. Results show that MODIS-Aqua band $1(620-670 \mathrm{~nm})$ is appropriate for predicting turbidity and total suspended matter concentrations using polynomial regression models, whilst band 2 is unadapted. Comparison between total suspended matter concentration 250-m resolution maps and mineral suspended matter 1000-m maps (generated by IFREMER) produced consistent results. A high correlation was obtained between turbidity measured in-situ and turbidity retrieved from MODIS-Aqua satellite data.
\end{abstract}

Keywords: Adour River plume; Turbidity; Suspended matter; Satellite sensing; MODIS; Remote sensing reflectance 


\section{Introduction}

The European Water Framework Directive (2000/60/EC) is intended to have a strategic role in water policy and aims at conserving and restoring the state of freshwater and coastal waters (Borja et al., 2006). It is based upon the status of biological, hydromorphological and physicochemical quality parameters. Among the physico-chemical parameters, turbidity (Turb., in NTU) is a relevant parameter to be measured. Turbidity can be defined as a decrease in the transparency of a solution due to the presence of coloured suspended and dissolved 
substances; accordingly the estimation of total suspended matter concentration (TSMc, in $\mathrm{mg} . \mathrm{l}^{-1}$ ) is of strong interest.

The Basque coastal waters, located near the Adour river mouth, are directly influenced by the freshwater discharge from the Adour river (Ferrer et al., 2009; Morichon and Dailloux, 2006; Stoichev et al., 2004) and are typical case 2 waters (Morel and Prieur, 1977). The Adour runoff variability leads to wide ranges of turbidity and TSMc in the adjacent coastal waters. Both parameters (Turb. and TSMc) are indicators of water pollution as they can negatively impact biological productivity and human health. In the presence of a river plume, stratification, nutrient pathways, light and circulation patterns are significantly altered (Hickey et al., 2005). Furthermore, as metallic pollutants are associated to sediments (Stoichev et al., 2004), the Adour estuary may represent a non-negligible contribution of contaminant input into the Bay of Biscay. Hence the turbidity of the Adour plume needs to be accurately monitored.

Conventional sampling methods are limited in terms of temporal and spatial coverage and often fail to characterize turbidity dynamics. Several studies have demonstrated that ocean colour satellite imagery, such as MODIS data, represents an effective alternative to these traditional sampling methods (Chen at al., 2007; Doxaran et al., 2009; Hu et al., 2004; Miller and McKee, 2004). In different local contexts, computations of empirical relationships between in-situ parameters of interest and reflectance measurements have been proposed (e.g.; Froidefond et al. 2002; Miller and McKee 2004; Ouillon et al., 1997). In the Bay of Biscay, such measurements have been carried out in the Gironde and Loire estuaries (Doxaran et al., 2002a, 2002b, 2003, 2009; Froidefond et al., 2004; Froidefond and Ouillon, 2005) but studies intending to monitor the dynamics of the Adour river plume using ocean colour satellite imagery are scarce (Ferrer et al., 2009; Morichon and Dailloux, 2006). 
As part of the MarCoast Project funded by the European Space Agency, synoptic maps of Mineral Suspended Matter (MSM, in mg. $1^{-1}$ ) are generated daily by IFREMER for the whole Bay of Biscay (URL: http://www.ifremer.fr/nausicaa/marcoast/index.htm). These maps are produced applying IFREMER empirical algorithms to SeaWiFS/MODIS/MERIS 1000-m resolution imagery. In a first step, chlorophyll concentrations are calculated from a Look-UpTable (Gohin et al., 2002). Then the concentration of MSM is derived from the inversion of a simple analytical model relating the water-leaving radiance to the water constituents, defined as pure water, Chlorophyll and MSM (Gohin et al., 2005), excluding Coloured Dissolved Organic Matter (CDOM). CDOM is considered as linearly related to MSM and Chlorophyll. Comparisons between suspended matter concentration maps derived from 250-m and 1000-m MODIS images are of interest for two reasons. The first reason is technical and related to ocean colour algorithms, e.g. the respective influences of selected wavelengths and spatial resolutions used to retrieve the concentrations of suspended matter. The second interest concerns the environmental monitoring and potential use of the $250-\mathrm{m}$ products in a $1000-\mathrm{m}$ operational chain.

In our study, we developed specific empirical algorithms in order to map turbidity and TSMc in the coastal waters influenced by the Adour plume. To achieve these objectives, an oceanographic survey (BATEL-1) was carried out in the Adour area to measure in-situ the turbidity, TSMc and seawater reflectance. Motivated by several studies that demonstrated the potential of Moderate Resolution Imaging Spectroradiometer-Aqua bands $1(645 \mathrm{~nm})$ and $2(859 \mathrm{~nm})$ to monitor water quality in estuarine and coastal waters (Chen et al., 2007; Doxaran et al., 2009; Hu et al., 2004; Miller and Mckee, 2004),we decided to test the efficiency of atmospherically-corrected 250-m surface reflectance bands 1 and 2 from the MODISAqua (MYD09 product). 
The methodology includes four successive steps. (1) Based on in-situ measurements, regional empirical relationships are established between remote sensing reflectance on one hand and TSMc and turbidity on the other hand. (2) The respective sensitivity of MODIS bands 1 and 2 to TSMc and water turbidity variations is assessed. (3) The quality of atmospheric corrections is tested, i.e. satellite and in-situ remote sensing reflectance data are compared, based on match-ups. (4) The selected algorithms are applied to the MYD09 (Level-2) product. The 250-m resolution maps are then related to the IFREMER 1000-m maps. Finally, TSMc retrieved from satellite data and measured in-situ sampling points are compared.

\section{Study area}

The study area is located in the South Est of the Bay of Biscay (Fig. 1a) where coastal waters continuously receive continental waters from the outflow plume of the Adour river (Fig. 1b, c).

\section{APPROXIMATE LOCATION OF FIGURE 1}

The Adour estuary $\left(43^{\circ} 30 \mathrm{~N}, 1^{\circ} 30 \mathrm{~W}\right)$ is a mesotidal system characterized by a tidal range between 2 and $5 \mathrm{~m}$ (Stoichev et al., 2004) and very energetic wave conditions (average significant wave height of $1.5 \mathrm{~m}$ and average peak wave period of 9 seconds (Abadie et al., 2005). The tidal influence can be observed up to $70 \mathrm{~km}$ upstream the mouth (Stoichev et al., 2004). The Adour watershed, covering about $17000 \mathrm{~km}^{2}$, connects the occidental Pyrenean piedmont to the Atlantic Ocean. The drainage basin is composed of the Adour, Bidouze, Gaves, Nive, Luy and Nivelle hydrographical contributor basins. The upstream part of the 
estuary flows through agricultural areas, while the downstream part is within the urban district of Bayonne and is subject to industrial inputs (Stoichev et al., 2004). The mean annual river discharge is about $300 \mathrm{~m}^{3} \cdot \mathrm{s}^{-1}$ and reaches $2000 \mathrm{~m}^{3} \cdot \mathrm{s}^{-1}$ during brief flood events (Stoichev et al., 2004).

The solid discharge of the Adour river is about 0.25 Mt. $\mathrm{yr}^{-1}$ (Maneux, 1998). The geomorphologic characteristics of the estuary, the hydrological features and the channelled waterways of the estuarine section lead to short residence time for both water and particles, ranging from a few hours to several days (Point et al. 2007; Villate et al., 1989). Therefore, sedimentation rates are low in the estuary so that most of the sediment inputs from the river is rapidly exported to the ocean (Maneux, 1999). As comparison, residence times for particles range from 12 to 24 months and 4 to 10 months in the Gironde and Loire estuaries, respectively (Etcheber et al., 2008). Point et al. (2007) estimated that $75 \%$ of the annual flux of suspended solids of the Adour river is exported to the ocean within 30-40 days.

\section{Material and methods}

3.1 In-situ measurements during the BATEL-1 survey

The BATEL-1 survey took place from the $4^{\text {th }}$ to the $14^{\text {th }}$ of June 2007 , onboard the "Côtes de la Manche" research vessel (INSU-CNRS). Biogeochemical and optical parameters were measured in 96 stations which extended about $45 \mathrm{~km}$ along-shore, and $35 \mathrm{~km}$ between the estuarine and marine waters in the cross-shore direction (Fig. 2a). The survey was conducted during river discharge $(\mathrm{Q})$ conditions typical of June $\left(\mathrm{Q}_{\mathrm{June}-2007}=385 \pm 67 \mathrm{~m}^{3} \cdot \mathrm{s}^{-1}\right.$ with $Q_{J u n e-m e a n}$ calculated over the period 1957- $\left.2009=312 \pm 189 \mathrm{~m}^{3} \cdot \mathrm{s}^{-1}\right)$ immediately after an important flood event $\left(\mathrm{Q}_{27 / 05 / 07}=710 \mathrm{~m}^{3} \cdot \mathrm{s}^{-1}\right)$. Measurements covered a spring/neap tide cycle. 


\section{APPROXIMATE LOCATION OF FIGURE 2}

\subsection{Optical measurements}

The optical properties of the coastal waters influenced by the Adour plume depend on both dissolved and particulate coloured substances. The optical signature of the coastal waters was quantified using the remote sensing reflectance $\left(\operatorname{Rrs}(\lambda)\right.$ in $\left.^{-1}\right)$ :

$$
\operatorname{Rrs}(\lambda)=\operatorname{Lw}(\lambda) / \operatorname{Ed}\left(\lambda, 0^{+}\right)
$$

where $\mathrm{Lw}\left(\mathrm{W} \cdot \mathrm{m}^{-2} \cdot \mathrm{sr}^{-1} \cdot \mathrm{nm} \mathrm{m}^{-1}\right)$ is the water leaving radiance and $\mathrm{Ed}\left(\mathrm{W} \cdot \mathrm{m}^{-2} \cdot \mathrm{nm}^{-1}\right)$ is the downwelling irradiance just above the water surface.

The in-situ remote sensing reflectance, $\left(\operatorname{Rrs}(\lambda)_{\text {in-situ }}\right)$, was measured using TriOS

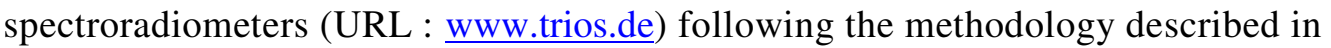
Froidefond and Ouillon (2005). One irradiance sensor (Ramses-ACC n ${ }^{\circ} 8108$ ) and one radiance sensor (Ramses-ARC ${ }^{\circ} 8091$ ) were used simultaneously to perform measurements with a spectral resolution of $5 \mathrm{~nm}$ between 350 and $950 \mathrm{~nm}$ (Fig 3b, d). At least 40 spectral measurements were recorded at each sampling site with the irradiance sensor placed on the roof of the boat and pointing the zenith (fig. 3a).

The radiance sensor was fixed onto a mini-catamaran at approximately $2 \mathrm{~cm}( \pm 1 \mathrm{~cm})$ below the water surface (Fig. 3c). This catamaran was tailor-made to minimize the influence of self-shading and to enable measurements away from the ship. The objective was to avoid the usual effects of hull reflection/shadow of the vessel during measurements (Froidefond and Ouillon, 2005). 


\section{APPROXIMATE LOCATION OF FIGURE 3}

As the TSMc was typically lower than $50 \mathrm{mg} . \mathrm{l}^{-1}$ (98\% of the TSMc measured during the survey), light attenuation within the first $2 \mathrm{~cm}$ was assumed to be negligible. Thus, we considered the upwelling radiance signal measured just below the water surface $(\operatorname{Lu}(\lambda,-2))$ in order to avoid sky reflection effects (Froidefond and Ouillon, 2005). Furthermore, all the optical measurements were performed in water depths higher than $5 \mathrm{~m}$, suppressing any bottom contamination (Chen et al., 2007).

As the TriOS spectroradiometers are calibrated for measurements in the air (Ohde and Siegel, 2003), the calculation of $\operatorname{Lw}\left(\lambda, 0^{+}\right)$must take into account both the variation in solid angle between the submerged and emerged measurements (caused by the variation in the refraction index), and signal transmission through the water-air interface reduced by Fresnel reflectance (Froidefond and Ouillon, 2005, Gitelson et al.; 2008):

$\operatorname{Lw}\left(\lambda, 0^{+}\right)=\mathrm{F} \times\left(\mathrm{t} / \mathrm{n}^{2}\right) \times \operatorname{Lu}(\lambda,-2)$

where the factor $\mathrm{n}$ is the real index of water refraction $(\mathrm{n} \approx 1.34$; Chang et al., 2003; Gordon and Morel, 1983), $\mathrm{t}$ is the radiance transmittance of the surface $(\mathrm{t} \approx 0.98$; Chang et al., 2003; Gitelson et al., 2008; Mobley, 1994) and F is the immersion factor of the solid angle of the TriOS $\left(\mathrm{F} \approx 1.796\right.$; Ohde and Siegel, 2003). The coefficient $\mathrm{F} \times \mathrm{t} / \mathrm{n}^{2}$ is equal to 0.98 . For each station, remote sensing reflectance was then calculated from the combination of equations (1) and (2):

$$
\operatorname{Rrs}(\lambda)_{\text {in-situ }}=0.98 \times \operatorname{Lu}(\lambda,-2) / \operatorname{Ed}\left(\lambda, 0^{+}\right)
$$




\subsection{Biogeochemical measurements}

1 litre samples of surface water were collected using Niskin bottles simultaneously to optical measurements. The total suspended matter concentrations were measured by filtration through pre-weighed Whatmam GF/F filters with a diameter of $4.7 \mathrm{~cm}$ and a nominal porosity of $0.7 \mu \mathrm{m}$. The filters were rinsed with $25-50 \mathrm{ml}$ of Milli-Q water to remove salt crystals, and then dried during 24 hours at $60^{\circ} \mathrm{C}$. Duplicate filters were used and averaged to determine the final weight in milligram per litre. The turbidity (Nephelometric Turbidity Units, NTU) was measured directly on the water sample, using a Turb 430IR nephelometer. This instrument has a measuring range between 0.01 and $1100 \mathrm{NTU}$ and an accuracy of $\pm 2 \%$. Temperature $\left({ }^{\circ} \mathrm{C}\right)$ and salinity (PSU) were measured using a $\mathrm{pH} / \mathrm{ISE} / \mathrm{DO} /$ conductivity multi 350i sensor.

\subsection{Simulated seawater reflectance in MODIS bands 1 and 2}

A statistical data processing, based on Tukey outliers (Tukey, 1977), was performed on the 40 $\operatorname{Rrs}(\lambda)_{\text {in-situ }}$ spectra recorded at each sampling site in order to remove erroneous measurements. On average, only one or two spectra were rejected for each station, showing the good accuracy of the in-situ measurements. A maximum of eight spectra were removed from a coastal station near Saint Jean de Luz Bay. The selected spectra were averaged to obtain the mean $\operatorname{Rrs}(\lambda)_{\text {in-situ }}$ spectrum for each sampling station. These $\operatorname{Rrs}(\lambda)_{\text {in-situ }}$ spectra were then used to compute the simulated remote sensing reflectance in the MODIS bands 1 $\left(\operatorname{Rrs}(\mathrm{B} 1)_{\text {sim }}\right)$ and $2\left(\operatorname{Rrs}(\mathrm{B} 2)_{\text {sim }}\right)$ by weighting $\operatorname{Rrs}(\mathrm{Bi})_{\text {in-situ }}$ with the relative spectral 
responses (RSR(Bi)) of MODIS-Aqua corresponding bands (URL:

ftp://ftp.mcst.ssai.biz/pub/permanent/MCST/FM1_RSR_LUT_07-10-01/):

$\operatorname{Rrs}(\mathrm{Bi})_{\operatorname{sim}}=\frac{\sum_{\lambda \mathrm{n}}^{\lambda 1}\left(\operatorname{Rrs}(\mathrm{Bi})_{\mathrm{in}-\mathrm{situ}} \times \operatorname{RSR}(\mathrm{Bi})\right)}{\sum_{\lambda \mathrm{n}}^{\lambda 1} \operatorname{RSR}(\mathrm{Bi})}$

where $\lambda 1$ to $\lambda n$ are the wavelengths within the bandwidth of band $i(i=1,2)$.

Thus, two simulated Rrs values (Rrs(B1) $)_{\text {sim }}$ and $\left.\operatorname{Rrs}(\mathrm{B} 2)_{\text {sim }}\right)$, corresponding to the two $250-\mathrm{m}$ MODIS bands (1 and 2) were calculated for each oceanographic station.

\subsection{Regression models}

Relationships between the water quality parameters (turbidity and TSMc) and simulated Rrs spectra, i.e. $\operatorname{Rrs}(\mathrm{B} 1)_{\text {sim }}, \operatorname{Rrs}(\mathrm{B} 2)_{\text {sim }}$, and ratios between $\operatorname{Rrs}(\mathrm{B} 1)_{\text {sim }}$ and $\operatorname{Rrs}(\mathrm{B} 2)_{\text {sim }}$ were established considering successively linear, exponential, polynomial (second order) and power regression models. The determination coefficient $\left(\mathrm{R}^{2}\right)$ was computed for each regression.

A variety of statistical and graphical criteria were used to evaluate agreement between the water property estimated using the different models $\left(\mathrm{P}_{\mathrm{est}}\right)$, and the actual water property measured in-situ $\left(\mathrm{P}_{\mathrm{in}-\mathrm{situ}}\right)$. The mean difference for each station $\left(\mathrm{E}_{\text {mean,i, }}\right.$, in $\left.\%\right)$ and the Root Mean Square Error (RMS in \%) were systematically computed following equations (6) and (7) (Gohin et al., 2002), respectively. The distribution of $E_{\text {mean,i }}$ i.e., the percentage of $E_{\text {mean,i }}<$ $30 \%$ (weak error) and $<50 \%$ (moderate error), was calculated and Relative Frequency Distribution plots (RFD) of best regression models were compared to RFD of $\mathrm{P}_{\text {in-situ- }}$ 
$\mathrm{E}_{\text {meani }}(\%)=\left[\frac{\mathrm{P}_{\text {est }, \mathrm{i}}-\mathrm{P}_{\mathrm{in}-\text { situ }, \mathrm{i}}}{\mathrm{P}_{\mathrm{in}-\mathrm{i} \text { itu }, \mathrm{i}}}\right] \times 100$

$\operatorname{RMS}(\%)=\sqrt{\frac{\sum_{\mathrm{i}=1}^{\mathrm{n}}\left(\frac{\mathrm{P}_{\text {est }, \mathrm{i}}-\mathrm{P}_{\mathrm{in}-\text { situ }, \mathrm{i}}}{\mathrm{P}_{\text {in-situ }, \mathrm{i}}}\right)^{2}}{\mathrm{~N}}} \times 100$

where $\mathrm{P}_{\text {est, }}$ is the estimated value of water property corresponding to the ' $i$ 'th in-situ observation $\left(\mathrm{P}_{\mathrm{in}-\mathrm{situ}, \mathrm{i}}\right)$ and $\mathrm{N}$ is the station number.

Finally, we validated the best models based on a jackknife resampling procedure (Burnham and Anderson, 2002), developped with R language (R Development Core Team, 2007). With a dataset of $\mathrm{N}$ data stations, the jackknife procedure recalculated the model $\mathrm{N}$ times, leaving out one station in turn. Each one of the regression models based on the ' $\mathrm{N}-1$ ' station was then applied to that excluded stations in order to produce a predicted water property value for each station. We evaluated the predictive power of the model with the coefficient of determination $\left(\mathrm{R}^{2} \mathrm{jac}\right)$ between the recorded and the jackknife-estimated water property.

\subsection{MODIS-Aqua 250-m imagery and atmospheric corrections}

Two MODIS sensors are currently active aboard the Terra and Aqua satellite platforms. Terra and Aqua orbits around the Earth are timed to pass from North to South across the equator over the Adour estuary in the morning and afternoon, respectively (URL:

http://modis.gsfc.nasa.gov/). MODIS data are thus recorded twice a day over the South Bay of Biscay in 36 spectral bands between 415 and $14235 \mathrm{~nm}$ and with spatial resolutions of 250-m ( 2 bands), 500-m (5 bands) and 1000-m (29 bands). 
The MODIS medium-resolution bands (250-m and 500-m bands) were originally designed as "sharpening" bands for land studies and cloud detection, and therefore have lower sensitivities than MODIS ocean bands. However, through comparison with other sensors including Landsat-7 ETM+, CZCS, and SeaWiFS, Hu et al. (2004) concluded that these bands provide sufficient sensitivity for water applications and are at least as useful for coastal ocean applications as CZCS. Furthermore, using cross-correlation between the MODIS 250-m and 1000-m bands from May 2003 to April 2006, Chen et al. (2007) showed that the vicarious calibration of satellite at-sensor 250-m radiance is adequate for mapping turbidity in coastal waters.

The atmospheric contribution (absorption, scattering, and attenuation by gases and aerosols) must be removed from the signal detected by the satellite sensor in order to retrieve the water remote-sensing reflectance $\left(\operatorname{Rrs}_{\text {sat }}\right)$. In this study, we assessed the efficiency of MODIS-Aqua surface reflectance bands 1 and 2 (MYD09 product, at 645 and $859 \mathrm{~nm}$, respectively) at 250meter resolution because MODIS Terra products are noisier than Aqua products (Chen et al., 2007; Hu et al., 2004). The MODIS surface reflectance, computed from the MODIS Level 1B bands 1 and 2, provides an estimate of a target reflectance as it would be measured at ground level in the absence of atmospheric scattering and absorption. It is daily recorded in bands 1 and 2 in a gridded $\mathrm{L} 2 \mathrm{G}$ product in the Sinusoidal projection (URL:

http://modis.gsfc.nasa.gov/) and is corrected from atmospheric effects. The atmospheric correction is based on the $6 \mathrm{~S}$ radiative transfer code which accounts for the surface/atmosphere bi-directional reflectance function BRDF (Vermote et al., 2002). MYD09 data recorded during the BATEL-1 oceanographic survey were downloaded from the MODIS-NASA website (URL: http://modis.gsfc.nasa.gov/) and processed in the following way:

1. Cloud free images were selected using MODIS 1000-m IFREMER maps; 
2. Using MODIS Reprojection Tool, MODIS 250-m numeric counts (NC(Bi) $\left.)_{\text {sat }}\right)$ were reprojected and spatially subset on the area of interest;

3. Using Matlab software, geolocated $\mathrm{NC}(\mathrm{Bi})_{\text {sat }}$ were then converted into satellite remote sensing reflectance $\left(\operatorname{Rrs}(\mathrm{Bi})_{\text {sat }}\right.$, in $\left.\mathrm{sr}^{-1}\right)$ based on equation (8) (Doxaran et al., 2009). The scale factor $1 / 1000$ is used to convert the satellite numeric count in satellite surface reflectance:

$\operatorname{Rrs}(\mathrm{Bi})_{\text {sat }}=\operatorname{Lw}(\lambda) / \operatorname{Ed}(\lambda) \approx\left(\mathrm{NC}(\mathrm{Bi})_{\text {sat }} / 10000\right) / \pi$

4. Several scripts, developed in Matlab, were used to generate and validate calibrated maps as follows: a) comparison between the satellite $\left(\operatorname{Rrs}(\mathrm{Bi})_{\text {sat }}\right.$; equation $\left.(8)\right)$ and simulated remote sensing reflectance $\left(\mathrm{Rrs}(\mathrm{Bi})_{\text {sim }}\right.$; equation (4)), measured during the cloud free days of the survey to validate the MYD09 product. The time-lag between in-situ and satellite measurements, i.e. the absolute time difference between in-situ and satellite measurements, was carefully checked ; b) application of the best algorithms obtained from in-situ measurements to convert $\operatorname{Rrs}(\mathrm{Bi})_{\text {sat }}$ into TSMc and turbidity at 250-m resolution $\left(\mathrm{TSMc}_{\mathrm{sat}}\right.$ and Turb.sat, respectively); c) cartography of TSMc and turbidity in the area of interest; d) comparison between MODIS synoptic maps obtained at 1000-m (IFREMER/Nausicaa server) and 250-m resolutions (MYD09). In turbid coastal waters, mineral suspended matters represent the major proportion of the total suspended matters in terms of weight, while the contributions of planktonic and detrital organic particles are low or even negligible. Thus, we considered that synoptic maps of TSMc and MSM can be quantitatively compared; e) comparison between in-situ and satellite-derived TSMc and turbidity in the same way as for remote sensing reflectance. 


\subsection{MODIS-Aqua 1000-m imagery}

Although the goals of this work were not to assess the performance of the algorithm applied to the 1000-m images, these products have been used for comparison considering their ability for operational monitoring. The IFREMER's method is based on the inversion of a simple equation of the radiative transfer, considering that chlorophyll concentration is known. The IFREMER procedure, applied to SeaWiFS, MODIS and MERIS satellite data, is slightly different from the method described in Gohin et al. (2005) as it involves two channels. The initial algorithm was based on the green channel only, giving the concentration of MSM derived from the reflectance at 555-nm (MSM(555)). This was consistent with an in situ data set collected on the continental shelf. The method led to obvious underestimation in the central and most turbid part of the plumes where the channel at $661 \mathrm{~nm}$ appeared to be more appropriate to retrieve MSM concentrations. Therefore the final algorithm switches from $\operatorname{MSM}(555)$ to $\operatorname{MSM}(661)$ depending on the MSM level. Low and high MSM concentrations are estimated from the 551-nm and 661$\mathrm{nm}$ bands, respectively. The threshold is fixed around $4 \mathrm{mg} \cdot \mathrm{l}^{-1}$. When the MSM concentrations retrieved from the 555-nm and 661-nm bands are both lower than $4 \mathrm{mg} . \mathrm{l}^{-1}$, the 555-nm band is used. In any other case the 661-nm band is used to give the final estimation of MSM.

\section{Results}

4.1 Water mass characteristics 
During the BATEL-1 survey, in-situ measurements of salinity, temperature, TSMc and turbidity showed wide variations, ranging from 0.1 to $33.7 \mathrm{PSU}, 17.0$ to $22.2^{\circ} \mathrm{C}$ (Fig. 2b), 0.3 to $145.6 \mathrm{mg} . \mathrm{l}^{-1}$ and 0.01 to $188.20 \mathrm{NTU}$, respectively. Only two estuarine stations showed TSMc higher than $50 \mathrm{mg} . \mathrm{l}^{-1}$ (corresponding to turbidity higher than $70 \mathrm{NTU}$ ), while $82 \%$ of the TSMc measured in situ were lower than $5 \mathrm{mg} . \mathrm{l}^{-1}$.

Considering temperature-salinity characteristics and location of the sampling points (Fig. 2), three main types of water masses were identified during the survey: 1) estuarine waters (Fig. 2, grey circle), with salinity lower than 8 PSU and temperature between 17 and 21 ${ }^{\circ} \mathrm{C}$ (Fig. 2b). These water masses showed the highest TSMc measured (from 11.1 to 145.6 mg..$^{-1}$ ) and high variations of temperature/salinity/TSMc; 2) seawaters subject to direct inputs of freshwater runoff (Fig. 2, light grey circle and referred to as "plume waters"), with salinity ranging from 17 to $28 \mathrm{PSU}$ and temperature between 18 and $22^{\circ} \mathrm{C}$. These waters, facing the Adour estuary, were characterized by TSMc between 3 and 16 mg. ${ }^{-1}$; 3) seawaters less or not affected by the Adour plume (Fig. 2, black circle and referred to as "less affected waters"), with salinity higher than 28 PSU, temperatures ranging between 18 and $22^{\circ} \mathrm{C}$ and the lowest TSMc measured $\left(0.3-5.6 \mathrm{mg} . \mathrm{l}^{-1}\right)$. These water masses were located both northward and southward to the estuary mouth. The most distal sampling point from the mouth (Fig. 2a) was characterized by a salinity of about 33.1 PSU, a temperature of $20.3{ }^{\circ} \mathrm{C}$ and TSMc values of about $0.5 \mathrm{mg} \cdot 1^{-1}$. For TSMc $\mathrm{c}_{\text {in-situ }}$ higher than $1 \mathrm{mg} . \mathrm{l}^{-1}$, a robust linear regression was obtained (Fig. 4, equation (9)) between in-situ measurements of TSMc and turbidity $\left(\mathrm{R}^{2}=0.996, \mathrm{n}=65, \mathrm{p}<0.001\right)$.

Turb $_{\text {in-situ }}=1.353 \times \mathrm{TSMc}_{\text {in-situ }}-1.044$ 
For $\mathrm{TSMc}_{\mathrm{in} \text {-situ }}$ values lower than $1 \mathrm{mg} . \mathrm{l}^{-1}$, the $\mathrm{TSMc}_{\text {in-situ }}$ explained only $7.5 \%$ of the variability in turbidity (Fig. $4, \mathrm{R}^{2}=0.075, \mathrm{n}=20, \mathrm{p}=0.200$ (not significant)).

\section{APPROXIMATE LOCATION OF FIGURE 4}

4.2 In-situ remote sensing reflectance spectra

At least $74 \operatorname{Rrs}(\lambda)_{\text {in-situ }}$ spectra, corresponding to the same number of sampling stations, were used to develop the empirical algorithms between in-situ turbidity, TSMc and remote sensing reflectance. A selection of 17 representative Rrs spectra, corresponding to the three types of water masses defined in section 4.1 is presented in Fig. 5.

The magnitude of the $\operatorname{Rrs}(\lambda)_{\text {in-situ }}$ spectra strongly increases with increasing $\operatorname{TSMc}_{\text {in-situ }}$ (Fig. 5). The three types of water masses are clearly discriminated, as well as most of the small TSMc variations observed in the "less affected" waters (Fig. 5, black line). For TSMc in-situ $_{\text {. }}$ varying from 0.5 to $45.8 \mathrm{mg} . \mathrm{l}^{-1}$, the Rrs spectra show a similar tendency with a clear maximum peak around $550 \mathrm{~nm}$. This peak slightly shifts toward a higher wavelength (575 $\mathrm{nm}$ ) for higher $\mathrm{TSMc}_{\mathrm{in}-\mathrm{situ}}$. A second and less pronounced increase is observed in the nearinfrared, around $825 \mathrm{~nm}$ (Fig. 5). These observations are in agreement with results obtained in the Gironde estuary for the same range of TSMc (Doxaran et al., 2002a). Four spectra, corresponding to $\mathrm{TSMc}_{\text {in-situ }}$ lower than $0.5 \mathrm{mg} . \mathrm{l}^{-1}$ and higher than $50 \mathrm{mg} . \mathrm{l}^{-1}$ show different shapes with maximum peaks shifting around 490 and $690 \mathrm{~nm}$, respectively (Fig. 5, dotted black and grey lines).

Overall, an increase of the remote sensing reflectance is observed when $\mathrm{TSMc}_{\mathrm{in} \text {-situ }}$ increases from 0.5 to $145.6 \mathrm{mg} . \mathrm{l}^{-1}$. Around the central wavelength of MODIS band 1 (Fig. 5), light absorption by pure water and coloured water constituents is weak so that light 
backscattering by suspended particles mainly contribute to the water reflectance. Thus, in Figure 5a, an increase in $\operatorname{Rrs}(\lambda)_{\text {in-situ }}$ from $3 \times 10^{-4}$ to $4 \times 10^{-2} \mathrm{sr}^{-1}$ is clearly observed with increasing $\mathrm{TSMc}_{\mathrm{in}-\mathrm{situ}}$, except for TSMc $\mathrm{c}_{\mathrm{in}-\mathrm{situ}}$ lower than $0.5 \mathrm{mg} \cdot \mathrm{l}^{-1}$. Beyond $50 \mathrm{mg} \cdot \mathrm{l}^{-1}$, the Rrs signal tends to saturate (Fig. 5, dotted lines) as observed in the SPOT-XS1 band (500$590 \mathrm{~nm}$ ) for turbidity higher than $250 \mathrm{mg} . \mathrm{l}^{-1}$ in the Gironde estuary (Doxaran et al., 2002a). Within MODIS spectral band 2 (Fig. 5), high absorption by pure water (Hale and Querry, 1973; Pope and Fry, 1997; Smith and Baker, 1981) leads to Rrs(B2) values lower than in MODIS band 1 and ranging between $2 \times 10^{-5}$ and $8 \times 10^{-3} \mathrm{sr}^{-1}$. However, using logarithmic scale, an increase of remote sensing reflectance is apparent when $\mathrm{TSMc}_{\mathrm{in} \text {-situ }}$ ranges from 0.5 to $145.6 \mathrm{mg} \cdot 1^{-1}$.

\section{APPROXIMATE LOCATION OF FIGURE 5}

Motivated by the observations described above, we decided to test regression analyses between (1) the entire set of samples (called "SS ${ }_{\mathrm{e}}$ ") and $\operatorname{Rrs}(\mathrm{B} 2)_{\mathrm{sim}}$ and (2) the set of samples corresponding to TSMc lower than $50 \mathrm{mg} \cdot 1^{-1}$ (called "SS${ }_{1}$ " and corresponding to a set of samples with a turbidity lower than $70 \mathrm{NTU})$ and $\operatorname{Rrs}(\mathrm{B} 1)_{\mathrm{sim}}, \operatorname{Rrs}(\mathrm{B} 2)_{\mathrm{sim}}$ and $\operatorname{Rrs}(\mathrm{B} 2)_{\mathrm{sim}} / \operatorname{Rrs}(\mathrm{B} 1)_{\text {sim }}$ ratio. We paid a special attention to points corresponding to TSMc lower than $0.5 \mathrm{mg} . \mathrm{l}^{-1}$ (ibid. for turbidity lower than $0.5 \mathrm{NTU}$ ).

\subsection{Evaluation of the regression analyses}

The highest determination coefficients $\left(\mathrm{R}^{2}>0.9, \mathrm{p}<0.001\right)$ were obtained using linear and polynomial regressions (Table 1a), respectively, between $\operatorname{Rrs}(\mathrm{B} 1)_{\text {sim }}$ and "SS,", and between $\operatorname{Rrs}(\mathrm{B} 2)_{\text {sim }}$ and "SS $\mathrm{e}_{\mathrm{e}}$ " and "SS". As an illustration, more than $97 \%$ of the variance 
in $\mathrm{TSMc}_{\mathrm{in}-\mathrm{situ}}$ is explained by $\operatorname{Rrs}(\mathrm{B} 1)_{\text {sim }}$ when considering a polynomial ( $2^{\text {nd }}$ order)

regression applied to the set of samples "SS" (Table 1a, Eq. II). No satisfactory regression (i.e., with a $\mathrm{R}^{2}$ higher than 0.8 ) was established when considering the $\operatorname{Rrs}(\mathrm{B} 2)_{\operatorname{sim}} / \operatorname{Rrs}(\mathrm{B} 1)_{\text {sim }}$ ratio, (not shown here).

\section{APPROXIMATE LOCATION OF TABLE 1}

4.4 Evaluation of models for $\mathrm{TSMc}_{\text {in-situ }}$ retrieval

Statistical criteria calculated between TSMc estimated by the various regressions and TSMc measured in-situ are summarized in Table 1b. Similar RMS were obtained from the six tested regression models (61\% to $77 \%$ for models I to VI). However, polynomial regressions distinctly led to better distributions of errors $\left(E_{\text {mean, }}\right)$ in comparison with linear models. For instance, $71 \%$ (57\%) of $\mathrm{E}_{\text {mean, }, \mathrm{a}}$ are lower than $30 \%$ with model VI (V). The polynomial regression using $\operatorname{Rrs}(\mathrm{B} 1)_{\text {sim }}$ (Eq. II) led to a better retrieval of $\mathrm{TSMc}_{\text {in-situ }}$ lower than $50 \mathrm{mg} . \mathrm{l}^{-1}$ (Table 1b, "SS,") than using Rrs(B2) sim $_{\text {s. }}$ (Eq. IV). Thus, $75 \%$ and $88 \%$ of the $\mathrm{E}_{\text {mean, }, \mathrm{i}}$ calculated using band 1 are lower than $30 \%$ and than 50\%, respectively. Similar statistical criteria (Table

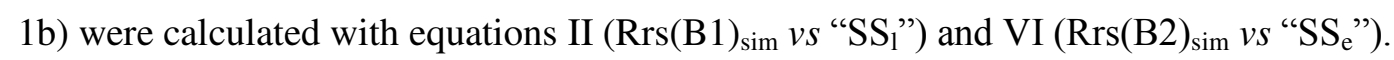
Accordingly, equations II and VI are the most efficient to retrieve TSMc below $50 \mathrm{mg} .1^{-1}$ and TSMc lower than $146 \mathrm{mg} . \mathrm{l}^{-1}$, respectively. All tested regression models poorly simulate $\mathrm{TSMc}_{\mathrm{in}-\text { situ }}$ lower than $0.5 \mathrm{mg} . \mathrm{l}^{-1}$. Ignoring these values (Table 1c), the resulting RMS were reduced by a factor 2 when using models II and VI (Table 1c: RMS $=34 \%$ and 37\%, respectively). The proportions of $\mathrm{E}_{\mathrm{mean}, \mathrm{i}}$ inferior to $30 \%$ and $50 \%$ showed also an increase. Relative frequency distribution plots (RFD, Fig. 6) reveal that distributions and modes for equations II and VI are close to the in situ distribution and mode. However, algorithm VI 
clearly overestimates the frequency of TSMcin-situ ranging between 1 and $2 \mathrm{mg} . \mathrm{l}^{-1}$. Finally, the high performances of polynomial models are confirmed by the jackknife resampling procedure (Table $1 \mathrm{~b}: \mathrm{R}^{2} \mathrm{jac}=0.967$ and 0.913 for equations II and VI, respectively).

\section{APPROXIMATE LOCATION OF FIGURE 6}

4.5 Evaluation of models for Turb.in-situ retrieval

As for TSMc, polynomial regressions between Rrs and Turb. performed better than linear regressions. Equations VIII, X and XII distinctly lead to better RMS and/or distributions of $E_{\text {mean,i }}($ Table $1 b)$. Similarly, all the tested regression models poorly simulate Turb.in-situ ${ }_{\text {lower }}$ than 0.5 NTU. Ignoring these values (Table 1c), the polynomial regression using $\operatorname{Rrs}(\mathrm{B} 1)_{\text {sim }}$ (Eq. VIII) leads to a better retrieval of Turb.in-situ lower than 70 NTU (Table 1b, "SS,") than using $\operatorname{Rrs}(B 2)_{\text {sim }}$ (Eq. X). Statistical criteria (Table 1b) calculated with equation VIII $\left(\operatorname{Rrs}(\mathrm{B} 1)_{\text {sim }} \text { vs "SS} \text { ") are better than with equation XII (Rrs(B2) }\right)_{\text {sim }}$ vs "SS "). However RMS calculated with both equations VIII and XII are satisfactory : RMS $=47 \%$ and 59\%, respectively. Good simulations of turbidity below 70 NTU and Turb. lower than 188 NTU can be then expected when applying these algorithms to Rrs in satellite bands 1 and 2, respectively.

Relative frequency plots (Fig. 6) show very good agreements between the model and measurements when considering algorithms VIII and XII. However, the RFD of equation VIII is closer to in-situ RFD. Indeed, with this equation we only obtain slight underestimation and overstimation of the frequency of Turb.in-situ ranging between 4 and 5 NTU and 5 and 10 NTU, respectively. Finally, high performance of equation VIII is confirmed by the 
jackknife procedure $\left(\right.$ Table $\left.1 \mathrm{~b}, \mathrm{R}^{2} \mathrm{jac}=0.940\right) . \mathrm{R}^{2} \mathrm{jac}$ calculated with equation XII is slightly lower (table $2 \mathrm{~b} ; \mathrm{R}^{2} \mathrm{jac}=0.884$ ). This indicates that equation VIII will be probably more efficient to simulate turbidity lower than 50 NTU than equation XII to compute Turb. ranging between 0.5 and 188 NTU.

4.6 Sensitivity of MODIS surface reflectance in bands 1 and 2

The first step before mapping TSMc and turbidity was to assess the efficiency of the MYD09 surface reflectance product, i.e. (1) to test the sensitivity of bands 1 and 2 to TSMc and turbidity variations then, (2) to evaluate the atmospheric correction by comparing the agreement between the satellite and in-situ remote sensing reflectances $\left(\operatorname{Rrs}(\mathrm{Bi})_{\text {sat }}\right.$ and $\left.\operatorname{Rrs}(\mathrm{Bi})_{\text {sim }}\right)$. Only two free-cloud days could be considered for the validation of ocean colour satellite product (the $6^{\text {th }}$ and the $11^{\text {th }}$ of June).

\section{APPROXIMATE LOCATION OF FIGURE 7 AND TABLE 2}

Table 2 lists $\operatorname{Rrs}(\mathrm{Bi})_{\text {sat }}$ sensitivity, i.e. remote sensing reflectance corresponding to one Numeric Count $\left(\mathrm{NC}(\mathrm{Bi})_{\mathrm{sat}}=1\right)$, obtained from equation (8). MODIS bands 1 and 2 had the same sensitivity, estimated at $3 \times 10^{-5} \mathrm{sr}^{-1}$. The range of $\operatorname{Rrs}(\mathrm{Bi})_{\text {sim }}$ values measured in situ for the bands 1 and 2 (Fig. 5), as well as the sensitivity range of $\operatorname{Rrs}(\mathrm{Bi})_{\text {sim }}$, are specified in this table. The sensitivity of $\operatorname{Rrs}(\mathrm{Bi})_{\text {sim }}$, defined by equation (10), is shown in Fig. 7:

$$
\operatorname{Rrs}(\mathrm{Bi})_{\operatorname{sim}} \text { sensitivit } y=\operatorname{Rrs}(\mathrm{Bi})_{\operatorname{sim}(\operatorname{Pin}-\text { situ }, 1)}-\operatorname{Rrs}(\mathrm{Bi})_{\operatorname{sim}(\operatorname{Pin}-\text { situ }, 2)}
$$

where $\mathrm{P}=$ Turbidity and $\mathrm{P}_{\text {insitu, } 1}>\mathrm{P}_{\text {in-situ,2. }}$. 
Results show that $\operatorname{Rrs}(\mathrm{B} 1)_{\text {sim }}$ increases from $3 \times 10^{-4}$ to $4 \times 10^{-2} \mathrm{sr}^{-1}$ (Fig. 5) while the corresponding sensitivity varies from $1 \times 10^{-7}$ and $1 \times 10^{-2} \mathrm{sr}^{-1}$. Rrs(B2) sim increases from $2 \times 10^{-}$ ${ }^{5}$ to $8 \times 10^{-3} \mathrm{sr}^{-1}$ (Fig. 5) with a sensitivity varying from $3 \times 10^{-8}$ to $3 \times 10^{-3} \mathrm{sr}^{-1}$. In both cases, $\operatorname{Rrs}(\mathrm{Bi})_{\text {sim }}$ sensitivity shows an exponential decrease tendency as turbidity decreases (Fig. 7). As $\operatorname{Rrs}(\mathrm{Bi})_{\text {sat }}$ is about $3 \times 10^{-5} \mathrm{sr}^{-1}$ (Table 2), and given the tendency curve (Fig. 7), it is expected that $\operatorname{Rrs}(\mathrm{B} 2)_{\text {sat }}$ is not sensitive to turbidity (or TSMc) variations ranging between 0.01 and $10 \mathrm{NTU}$ (or mg. ${ }^{-1}$ ). However, these variations of turbidity and TSMc cover approximately $90 \%$ of the turbidity and TSMc values measured during the survey. Despite

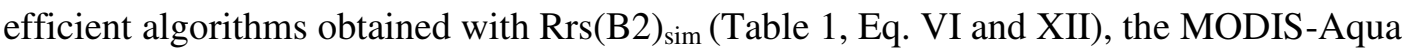
band 2 is therefore unsuitable for our study. Light absorption by pure water is much lower within MODIS band 1 than MODIS band 2, while light backscattering is rather flat spectrally from band 1 to band 2 . As a result, the values and sensitivity of Rrs are higher in band 1 than in band 2 (Table 2 and Fig. 5 and 7). The MODIS sensitivity of $3 \times 10^{-5} \mathrm{sr}^{-1}$ is sufficient to reconstitute the quasi whole turbidity (or TSMc) variations measured in-situ (Fig. 7). Only the lowest values of turbidity and TSMc (i.e. values lower than 1 NTU and $1 \mathrm{mg} . \mathrm{l}^{-1}$ ) may not be detected using MODIS band 1. Accordingly, on the $6^{\text {th }}$ and $11^{\text {th }}$ of June 2007, the influence of the Adour turbid plume was clearly observed using MYD09 band 1 but was not detected using band 2 (Fig. 8). The uncertainty in atmospheric corrections was therefore only assessed for MODIS-Aqua band 1.

\section{APPROXIMATE LOCATION OF FIGURE 8}

\subsection{Assessment of MYD09 atmospheric corrections}


The $6^{\text {th }}$ of June, $\operatorname{Rrs}(\mathrm{B} 1)_{\text {sat }}$ and $\operatorname{Rrs}(\mathrm{B} 1)_{\text {sim }}$ were highly correlated for a time lag (i.e. absolute time difference between satellite and in-situ measurements) lower than 2 hours (Fig. 9a, grey surface). In contrast, on the same date, $\operatorname{Rrs}(\mathrm{B} 1)_{\text {sat }}$ significantly overestimated the $\operatorname{Rrs}(\mathrm{B} 1)_{\text {sim }}$ values at stations B32 to B36 (Fig. 9a) where the time lags between in-situ and satellite data exceeded 4 hours. During this time interval (up to 6 hours between the in-situ and satellite measurements), tidal variations (ebb tide) may have led to the south-westward transport of suspended matter in the marine water at the time of the satellite acquisition, which can probably explain the increase in $\operatorname{Rrs}(\mathrm{B} 1)$ observed. Variations in the particle type and size, thus optical properties, and/or changes in the atmospheric composition during the time lags may be additional explanations. The $11^{\text {th }}$ of June, a high correlation was again obtained between $\operatorname{Rrs}(\mathrm{B} 1)_{\text {sat }}$ and $\operatorname{Rrs}(\mathrm{B} 1)_{\text {sim }}$ when considering stations with time lags lower than 2 hours (Fig. 9b). Although satellite data slightly overestimate Rrs(B1) $)_{\text {in-situ }}$ at sampling points B46 to B50, tendencies of the in-situ Rrs(B1) values are well respected. Rrs(B1) sim measured at stations B45, B44 and B48 (Fig 9b), 3 to 5 hours after the satellite overpassed, do not show a significant difference with $\operatorname{Rrs}(\mathrm{B} 1)_{\text {sat. }}$ This probably results from the location of these stations, i.e. mainly away from the direct influence of the Adour plume and from the moment of the tide (flood tide which limits the seaward extension of the plume) (Fig. 8c, d and 9b). If the comparison between satellite and in-situ data is limited to time lags lower than 2 hours and to stations located outside the plume influence on the $6^{\text {th }}$ and $11^{\text {th }}$ of June, a strong linear relationship is clearly obtained between $\operatorname{Rrs}(\mathrm{B} 1)_{\text {sat }}$ and $\operatorname{Rrs}(\mathrm{B} 1)_{\mathrm{in}-\mathrm{situ}}\left(\mathrm{R}^{2}=0.952, \mathrm{n}=15, \mathrm{p}<\right.$ $0.001)$.

APPROXIMATE LOCATION OF FIGURE 9 
4.8 Comparison between synoptic satellite maps (250-m and 1000-m resolution) and in-situ sampling points

Taking into account the sensitivity of MODIS bands 1 and 2 and the evaluation of various regressions, polynomial regressions applied on $\operatorname{Rrs}(\mathrm{B} 1)_{\text {sat }}($ Table 1, eq. II and VIII) were selected to map TSMc and turbidity. Equations II and VIII have the following forms: TMSc $=12450 \mathrm{x}^{2}+666.1 \mathrm{x}+0.48$ and Turb. $=26110 \mathrm{x}^{2}+604.5 \mathrm{x}+0.24$, respectively, with $\mathrm{x}$ the measured Rrs(B1) sat $\operatorname{signal.~The~synoptic~maps~of~suspended~matters~obtained~at~250-m~and~}$ 1000-m resolutions give consistent results (see Fig. 10b and f in comparison with Fig. 10a and e).

\section{APPROXIMATE LOCATION OF FIGURE 10}

The 250-m TSMc map obtained on the $6^{\text {th }}$ of June is particularly detailed in comparison to the 1000-m map. Figure 10c shows comparison of TSMc 250-m and MSM 1000-m along a profile parallel to the plume extension. Suspended matter concentrations are very similar, ranging between 1 and $14 \mathrm{mg} \cdot \mathrm{l}^{-1}$. However, the standard SeaDAS cloud flag (Gohin et al., 2002, 2005) applied to 1000-m pixel (Fig. 10a, white pixels) did not allow a comparison of concentrations very close to the coast. Furthermore, an underestimation of $\operatorname{TSMc}_{\mathrm{sat}}(250-\mathrm{m})$ in comparison to MSM (1000-m) is observed at low concentrations ranging from 1.5 to $4 \mathrm{mg} . \mathrm{l}^{-1}$. Along the TSMc 250-m profile, an important TSMc decrease is observed at $0.05^{\circ}$ from the coastline (Fig. 10c: Atm. Corr.). It corresponds to an area of water with lower concentrations (Fig. 10b) and may be linked to a local problem of atmospheric correction (Fig. 8a, under the sampling points B30, B31 and L2).

Qualitatively, the two profiles show similar seaward decrease in suspended matter 
concentrations. The arbitrary delimitation of the extension of the plume by a concentration of $1.5 \mathrm{mg} \cdot \mathrm{ll}^{1}$ leads to a larger extension of the 1000 -m plume $\left(0.17^{\circ}\right)$ in comparison to the 250-m plume $\left(0.14^{\circ}\right)$

The 1000-m and 250-m maps show a rather good agreement with in-situ measurements (Fig 9c). Considering the strong dynamic of the plume system, a robust validation of satellite products would have required a time lag lower than 2 hours between satellite and field observations. Unfortunately, only three $\mathrm{TSMc}_{\mathrm{in} \text {-situ }}$ measurements were recorded within this time lag (Fig 9c). At these stations (B21, B22 and B23), TSMc $c_{\text {in-situ }}$ and $\mathrm{TSMc}_{\text {sat }}$ are very similar. Despite a lack of in-situ data, consistent $\mathrm{TSMc}_{\mathrm{sat}}$ and $\mathrm{MSM}_{\mathrm{sat}}$ values are observed at stations L1 and L2. Furthermore, a high correlation is obtained between Turb ${ }_{\text {.in-situ }}$ and Turb.sat at these two stations (Fig. 9e). As TSMc and turbidity maps are very similar (Fig 10b and d) a high agreement between $\mathrm{TSMc}_{\mathrm{in}-\mathrm{situ}}$ and $\mathrm{TSMc}_{\mathrm{sat}}$ is also expected at sampling points $\mathrm{L} 1$ and L2. Finally, and despite an underestimation of the in-situ value, the increasing turbidity observed in-situ at station L3 is well retrieved by the satellite. The same underestimation can be envisaged for the $\mathrm{TSMc}_{\mathrm{sat}}$ value.

On the $11^{\text {th }}$ of June, the 1000-m and 250-m maps also show similar tendencies (Fig. 10e, f). Along a cross-shore profile (Fig. 10g), lower values of $\mathrm{TSMc}_{\text {sat }}(250-\mathrm{m})$ in comparison to MSM (1000-m) are retrieved for concentrations of suspended matter ranging from 5 to 7 mg..$^{-1}$. A good agreement is observed between in-situ measurements and satellite observations at 1000-m and 250-m resolutions (Fig. 9d). Although few TSMc $\mathrm{in}_{\mathrm{in} \text { situ }}$ are available for validation of the $250-\mathrm{m}$ map, similar $\mathrm{TSMc}_{\mathrm{in}-\text { situ }}$ and $\mathrm{TSMc}_{\mathrm{sat}}$ values are obtained at stations B45 to B48 (outside the plume influence) and at station B40 (time lag $<2 \mathrm{~h}$ ). Turb $_{\text {in-situ }}$ and Turb $_{\text {sat }}$ are also well correlated at stations B51, B46 and B49 (Fig. 9f, time lag < 2h) and similar results can be expected for $\mathrm{TSMc}_{\text {sat }}$. Finaly, as already observed on the remote 
sensing reflectance (Fig. 9b), satellite products slightly overestimate the Turb. .in-situ $_{\text {at }}$ at sampling points B41 and B50.

When only considering in-situ measurements carried out within a time lag of 2 hours before or after the satellite overpassed and outside the plume influence on the $6^{\text {th }}$ and $11^{\text {th }}$ of June, strong linear relationships were obtained between $\mathrm{TSMc}_{\mathrm{in}-\mathrm{situ}}$ and $\mathrm{TSMc}_{\mathrm{sat}}, \mathrm{TSMc}_{\mathrm{sat}}$ and $\mathrm{MSM}_{\text {sat }}$, and Turb in-situ $_{\text {and }} \operatorname{Turb}_{\text {sat }}\left(\mathrm{R}^{2}=0.967, \mathrm{n}=8, \mathrm{p}<0.001, \mathrm{R}^{2}=0.902, \mathrm{n}=14, \mathrm{p}<0.001\right.$ and $\mathrm{R}^{2}=0.926, \mathrm{n}=15, \mathrm{p}<0.001$, respectively).

\section{Discussion}

\subsection{Algorithm development}

High correlations were obtained between water reflectances simulated within MODIS bands 1 and 2 and "SS", and also between $\operatorname{Rrs}(\mathrm{B} 2)_{\text {sim }}$ and " $\mathrm{SS}_{\mathrm{e}}$ " when using polynomial regression models (Table 1a, $\mathrm{R}^{2}>0.950$ ). However, these algorithms were not adapted to retrieve $\mathrm{TSMc}_{\text {in-situ }}$ (Turb.in-situ) lower than $0.5 \mathrm{mg} .1^{-1}$ (NTU). This failure may be due to: (1) in-situ measurement errors. Indeed, within this range of concentrations we observed a poor correlation between turbidity and TSMc measured in-situ (Fig. 4); (2) the difficulty itself to retrieve low concentrations from low reflectance values associated to significant uncertainties. Over the small range of concentrations, a small error rapidly leads to a large relative error. Polynomial regressions using $\operatorname{Rrs}(\mathrm{B} 1)_{\text {sim }}$ led to better retrieval of $\mathrm{TSMc}_{\mathrm{in}-\mathrm{situ}}(\mathrm{Turb}$.) lower than $50 \mathrm{mg} . \mathrm{l}^{-1}$ (70 NTU) than using Rrs(B2) $)_{\text {sim }}$ (Table 1c). RMS errors calculated using equations II and VIII were quite satisfactory (Table 1c, RMS $=34 \%$ and RMS $=47 \%$, respectively). 
Considering the whole set of water samples ("SS ${ }_{\mathrm{e}}$ ”, Table 1c), $\operatorname{Rrs}(\mathrm{B} 2)_{\mathrm{sim}}$ was efficient to

retrieve TSMc ranging from 0.5 to $146 \mathrm{mg} . \mathrm{l}^{-1}$ and turbidity from 0.5 to $188 \mathrm{NTU}$ (RMS = $37 \%$ and RMS $=59 \%$, respectively). During the BATEL-1 survey, only two estuarine stations showed TSMc higher than 50 mg..$^{-1}$ (Turb. > 70 NTU) and the statistical representativity of these estuarine sampling points is questionable. Furthermore, in this range of concentrations, high light absorption by suspended matter may have resulted in significant errors on the remote sensing reflectance signal measured below the water surface (Froidefond and Ouillon, 2005). However, the determination coefficient obtained with the jackknife resampling procedure confirmed the reliabilityof regressions VI and XII (Table 1c, $\mathrm{R}^{2} \mathrm{jac}=$ 0.913 and $\left.\mathrm{R}^{2} \mathrm{jac}=0.884\right)$. Unfortunately, as band 2 sensitivity is insufficient to detect TSMc (turbidity) variations ranging between $\sim 0.01$ and $10 \mathrm{mg} \cdot \mathrm{l}^{-1}$ (NTU), the MYD09 band 2 product seems inadequate to monitor the influence of the turbid plume in the Adour coastal zone (Table 2 and Fig. 7). Indeed, during the BATEL-1 survey 85\% of the TSMc measured in-situ ranged between 0 and $5 \mathrm{mg} . \mathrm{l}^{-1}$. Furthermore, "plume waters" were characterized by TSMc between 2.9 and 9.4 mg. $1^{-1}$ (part 4.1, Fig. 2a).

One approach may be to switch from band 1 to band 2, depending on the TSMc level (ibid. for turbidity). This method is used in the IFREMER algorithm (see section 3.7) which switches from 555 to $661 \mathrm{~nm}$ to retrieve MSM concentrations at 1000-m resolution. Thus, the initial algorithm may be based on the red channel only (band 1), leading to

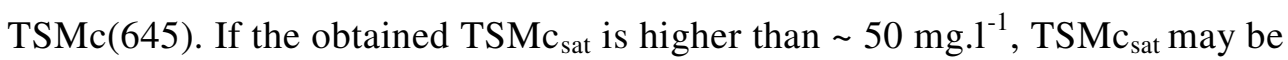
recomputed using the near-infrared band 2 centered at $859 \mathrm{~nm}$. However, other in-situ measurements would be necessary to fix more precisely the switching threshold and validate this methodology. In this study, we only used MODIS band 1 to map TSMc and turbidity. Chen et al. (2007), who used MODIS 250-m data (Level 1B, not atmospherically 
corrected), also recommended the use of band 1 to map turbidity, whilst their best retrieval algorithm for the Tampa Bay study area was based on a power regression model.

\subsection{Satellite-based maps}

Due to the high spatial and temporal variability in water and atmosphere properties encountered in coastal environments (Chen et al., 2007), the time lag between in-situ and satellite measurements is a key parameter to be taken into account when assessing the atmospheric corrections applied to ocean colour satellite data. Therefore, tidal variations, changes of the spatial orientation of the plume, variations in particle type and size, and changes in the atmospheric composition probably explain the observed shift between $\operatorname{Rrs}(\mathrm{B} 1)_{\text {sat }}$ and $\operatorname{Rrs}(\mathrm{B} 1)_{\text {sim }}$ at stations directly influenced by the Adour plume when the time lag exceeded two hours (Fig. 9a, b). In contrast, we obtained a good agreement between $\operatorname{Rrs}(\mathrm{B} 1)_{\text {sat }}$ and $\operatorname{Rrs}(\mathrm{B} 1)_{\text {sim }}$ when the time lag was below two hours and considering sampling points outside the direct influence of the Adour plume, on $6^{\text {th }}$ and $11^{\text {th }}$ of June $\left(R^{2}=0.952, n\right.$ $=15, \mathrm{p}<0.001)$. Despite insufficient paired observations preventing a validation of the MYD09 product, we selected the polynomial regression models (Table 1, eq. II and VIII) to map turbidity and TSMc the $6^{\text {th }}$ and $11^{\text {th }}$ of June.

The TSMc maps obtained at 250-m resolution were concordant with the 1000-m maps and provided considerable details on the TSMc distribution and plume orientation, notably on the $6^{\text {th }}$ of June (Fig. 10a, b). The analysis of transects along the plumes showed slightly lower levels of TSMc mapped with a resolution of 250-m comparatively to the 1000-m MSM IFREMER products, especially for TSMc ranging between 1.5 and $4 \mathrm{mg} \cdot \mathrm{l}^{-1}\left(6^{\text {th }}\right.$ of June) and between 5 and $7 \mathrm{mg} \cdot \mathrm{l}^{-1}$ ( $11^{\text {th }}$ of June). However, on both days, we found a very good 
agreement between the suspended variations retrieved from the two satellite maps (Fig. 9c, $f$ and 10c, g).

Despite the good determination coefficients obtained between $\mathrm{TSMc}_{\mathrm{in} \text {-situ }}$ and $\mathrm{TSMc}_{\mathrm{sat}}\left(\mathrm{R}^{2}=\right.$ 0.967, $\mathrm{n}=8, \mathrm{p}<0.001)$ and Turb.in-situ and Turb.sat $\left(\mathrm{R}^{2}=0.926, \mathrm{n}=15, \mathrm{p}<0.001\right)$, the limited number of comparison points does not allow a robust validation of the developed polynomial algorithms (Eq. II and VIII). However, these first results are very auspicious. Furthermore, the good agreement between the MODIS 250-m and IFREMER MODIS 1000-m maps is also promising, as IFREMER algorithms have been tested on large data sets representative of several coastal areas in the eastern Bay of Biscay (Gohin et al., 2005).

An important question is the broader applicability of the algorithms developed. If seasonal changes in the size, shape and composition of the suspended matter significantly impact the particle optical properties, the polynomial regressions may only be valid during the summer season. In order to have a first idea of the robustness of equation II, comparisons between Modis 250-m and 1000-m data products were realized for different seasonal and outflow conditions (Fig. 11). Two kinds of comparison were performed: 1) TSMc and MSM were extracted at one fixed point, near the estuary mouth, on 159 MODIS images recorded from 2006 to 2009; 2) comparative profiles were realized on a selection of 4 days with different hydroclimatical conditions. First comparisons show a very good agreement between TSMc and MSM extracted near the mouth (Fig.11a). Similar variations of suspended matter concentrations are clearly retrieved from 1000-m and 250-m resolution maps, over the four years. However, an underestimation of TSMc in comparison to MSM is observed for suspended matters concentrations higher than $30 \mathrm{mg} \cdot \mathrm{l}^{-1}$. Along profiles from the mouth to the limit of the plume (Fig.11b), we observed very similar variations of TSMc and MSM, except on February 2, 2007, when the Adour plume was more turbid. Equation II has been developed to retrieve TSMc up to $45 \mathrm{mg} . \mathrm{l}^{-1}$ (section 4.4). But based on these last observations, equation 
II seems to be applicable for different seasonal and outflow conditions, except for suspended matter concentrations higher than $\sim 30 \mathrm{mg} . \mathrm{l}^{-1}$ where it is more difficult to draw conclusions. It is not straightforward to determine whether MSM concentrations obtained from MODIS 1000-m maps are overestimated or TSMc retrieved from MODIS 250-m maps are underestimated. In addition, some ground-truthing would be necessary to validate or improve the algorithms developed in this study.

\section{APPROXIMATE LOCATION OF FIGURE 11}

\section{Conclusions}

In-situ measurements of the seawater reflectance, TSMc and turbidity carried out in the Adour river plume were used to develop regional algorithms then produce synoptic maps of these parameters using MODIS satellite data. The results obtained show that MODIS-Aqua band 1, at 250-m resolution and atmospherically corrected, is appropriate to retrieve turbidity and TSMc using the following second order polynomial regression models: TMSc $=12450$ $\mathrm{x}^{2}+666.1 \mathrm{x}+0.48$ and Turb. $=26110 \mathrm{x}^{2}+604.5 \mathrm{x}+0.24$. In spite of high correlations observed between $\operatorname{Rrs}(\mathrm{B} 2)_{\text {sim }}$ and Turb.in-situ $\left(\mathrm{TSMc}_{\mathrm{in}-\mathrm{situ}}\right)$, we found that the MODIS-Aqua band 2 is not sensitive enough to detect turbidity (TSMc) variations between 0.01 and 10 NTU (mg. $1^{-1}$ ). Polynomial regression models were applied to the MODIS MYD09 band 1 product to map turbidity and TSMc distributions in the South Bay of Biscay. Despite their different correction procedures, TSMc maps at 250-m resolution and MSM maps at 1000-m showed good consistency, except for suspended matters concentrations higher than $30 \mathrm{mg} . \mathrm{l}^{-}$

${ }^{1}$. The comparison between these maps on the $6^{\text {th }}$ and $11^{\text {th }}$ of June 2007 highlighted detailed 
features than can be extracted from the data recorded at 250-m spatial resolution to study both the TSMc distribution and plume orientation. Due to a lack of match-ups between in-situ and satellite data, our results did not allow a full validation of the MYD09 atmospheric corrections nor the polynomial algorithms developed in this study. However, the good agreement between the MODIS 250-m and the MODIS 1000-m maps, as well as the good relationships obtained between in-situ and satellite water quality parameters are auspicious. Three major challenges should now be addressed in order to develop an operational monitoring of turbidity in coastal waters of the eastern Bay of Biscay using the MYD09 product. First, Rrs(B1) $)_{\text {sat }}$ and $\operatorname{Rrs}(\mathrm{B} 1)_{\text {sim }}$ should be compared on a larger data set to further validate the atmospheric corrections applied to MODIS data. For instance, all the in-situ remote sensing reflectance measurements carried out during the last ten years in the estuary and turbid plume of the Gironde (e.g. Doxaran et al., 2002, 2003; Froidefond et al., 2004, 2005) should be merged. Second, stability and uncertainty of the polynomial algorithms over the year must be clarified. Additional TSMc $\mathrm{c}_{\mathrm{in}-\mathrm{situ}}$ and Turb. in-situ measurements as well as other comparisons between 1000-m and 250-m MODIS maps should be made. The third challenge will be to develop a toolbox to routinely generate synoptic maps of TSMc and turbidity in the Adour estuary area. A better understanding of the displacement of Adour turbid plume and its influence on the adjacent coastal waters is expected combining MODIS imagery to hydrodynamic models forced with hydro-climatologic data such as river flow, wind and tidal current.

\section{Acknowledgements}

This research was supported by the Technical Littoral Center of the Lyonnaise des eaux of Biarritz, the Ministry of Science and Innovation (Spanish Government, Ref.: ESP2006- 
10411) and by the Funds for Aquitania-Euskadi cooperation (Basque Government and Aquitaine Region).

\section{References}

Abadie, S.; Butel, R.; Dupuis, H., and Briere, C., 2005. Statistical parameters of waves on the South Aquitaine coast. CR-Geoscience, 337 (8), 769-776.

Binding, C.E., Bowers, D.G., Mitchelson-Jacob E.G, 2005. Estimating suspended sediment concentration from ocean colour measurements in moderately turbid waters; the impact of variable particle scattering properties. Remote Sensing of Environment 94 (3), 373383.

Borja, Á., Galparsoro, I., Solaun, O., Muxika I., Tello, E.M., Uriarte, A., Valencia, V., 2006. The European Water Framework Directive and the DPSIR, a methodological approach to assess the risk of failing to achieve good ecological status. Estuarine, Coastal and Shelf Science 66 (1-2), 84-96.

Burnham, K.P., Anderson, D.R., 2002. Model Selection and Multimodel Inference: A Practical Information - Theoretic Approach, $2^{\text {nd }}$ edn. Springer, New York.

Chang, G.C., Dickey, T.D., Mobley, C.D., Boss, E., Pegau, W.S., 2003. Toward closure of upwelling radiance in coastal waters. Applied Optics 42 (9), 1574-1582.

Chen, Z., Hu, C., Muller-Karger, F., (2007). Monitoring turbidity in Tampa bay using MODIS/Aqua 250-m imagery. Remote Sensing of Environment 109 (2), 207-220. 
Defant, A., 1961 : Physical Oceanography. Vol. I. Pergamon, 729 pp.

Doxaran, D., Froidefond, J.M., Lavender, S., Castaing, P., 2002a. Spectral signature of highly turbid waters. Application with SPOT data to quantify suspended particulate matter concentrations. Remote Sensing of Environment 81 (1), 149-161.

Doxaran, D., Froidefond, J.M., Castaing, P., 2002b. A reflectance band ratio used to estimate suspended matter concentrations in sediment-dominated coastal waters. International Journal of Remote Sensing 23 (23), 5079-5085.

Doxaran, D., Froidefond, J.M., Castaing, P., 2003. Remote-sensing reflectance of turbid sediment-dominated waters. Reduction of sediment type variations and changing illumination conditions effects by use of reflectance ratios. Applied Optics 42 (15), 2623-2634.

Doxaran, D., Froidefond, J.M., Castaing, P., Babin, M., 2009. Dynamics of the turbidity maximum zone in a macrotidal estuary (the Gironde, France): Observations from field and MODIS satellite data. Estuarine, Coastal and Shelf Science 81, 321-332.

Etcheber, H., Taillez, A., Abril, G., Garnier, J., Servais, P., Moatar, F., Commarieu, M.V., 2008. Particulate organic carbon in the estuarine turbidity maxima of the Gironde, Loire and Seine estuaries: origin and lability. Hydrobiologia 588, 245-259. 
Ferrer, L., Fontán, A., Mader, J., Chust, G., González, M., Valencia, V., Uriarte, A., Collins, M.B., 2009. Low salinity plumes in the oceanic region of the Basque Country. Continental Shelf Research, doi: 10.1016/j.csr.2008.12.014.

Froidefond, J.M., Gardel, L., Guiral, D., Parra, M., Ternon, J-F., 2002a. Spectral remote sensing reflectances of coastal waters in French Guiana under the Amazon influence. Remote Sensing of Environment 80 (2), 225-232.

Froidefond, D., Doxaran, D., 2004. Télédétection optique appliquée à l'étude des eaux côtières. Télédétection 4 (2), 579-597.

Froidefond, J.M., Ouillon, S., 2005. Introducing a mini-catamaran to perform reflectance measurements above and below the water surface. Optics Express 13 (3), 926-936.

Gitelson, A.A., Dall'Olmo, G., Moses, W., Rundquist, D.C., Barrow, T., Fisher, T.R., Gurlin, D., Holz, J., 2008. A simple semi-analytical model for remote estimation of chlorophyll-a in turbid waters: Validation. Remote Sensing of Environment 112 (9), 3582-3593

Gohin F., Druon J.N., Lampert L., 2002. A five channel chlorophyll concentration algorithm applied to SeaWiFS data processed by SeaDAS in coastal waters. International Journal of Remote Sensing 23 (8), 1639-1661.

Gohin, F., Loyer, S., Lunven, M., Labry, C., Froidefond, J.M., Delmas, D., Huret, M., Herbland, A., 2005. Satellite-derived parameters for biological modelling in coastal waters: 
illustration over the eastern continental shelf of the Bay of Biscay. Remote Sensing of Environment 95 (1), 29-46.

Gordon, H.R., Morel, A., 1983. Remote assessment of ocean color for interpretation of satellite visible imagery: a review. Springer Verlag, New-York, pp.114.

Hale, G.M., and Querry, M.R., 1973. Optical constants of water in the $200 \mathrm{~nm}$ to $200 \mu \mathrm{m}$ wavelength region. Applied Optics 12, 555-563.

Hu, C., Chen, Z,. Clayton, T.D., Swarzenski, P., Brock J.C., Muller-Karger F., 2004. Assessment of estuarine water-quality indicators using MODIS medium-resolution bands: Initial results from Tampa Bay, FL. Remote Sensing of Environment 93 (3), 423-441.

Hickey, B., Geier, S., Kachel, N., MacFadyen, A., 2005. A bi-directional river plume: the Colombia in summer. Continental Shelf Research 25, 1631-1656

Maneux, E., Clement, O., Charriton, X., Dumas, J., Barriere 1998. Erosion mécanique des sols et transports fluviaux de matières en suspension : application des systèmes d'information géographique dans les bassins versants de l'Adour, de la Dordogne et de la Garonne, Thèse, université Bordeaux-1, no 1897, 254 p.

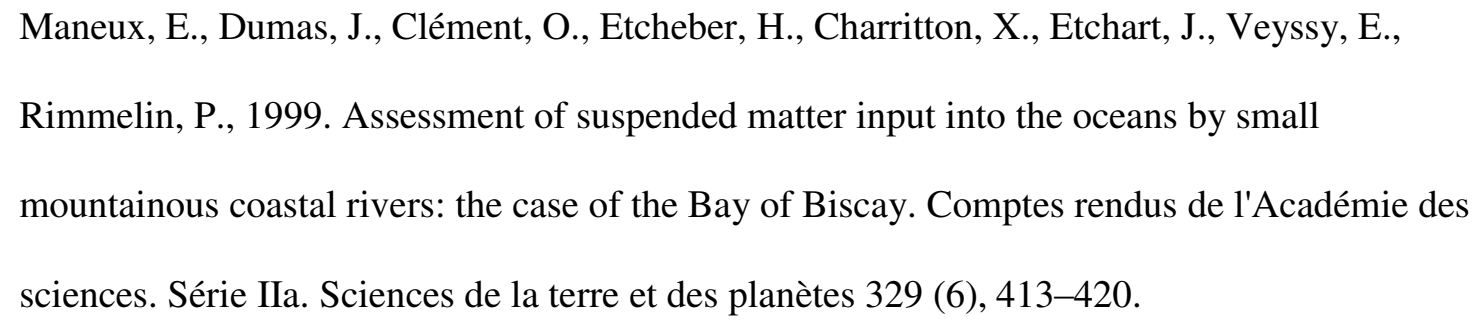


Miller, R.L., McKee, B.A. 2004. Using MODIS Terra 250 m imagery to map concentrations of total suspended matter in coastal waters. Remote Sensing of Environment 93 (1-2), 259266.

Mobley, C. D., 1994. Light and Water: Radiative Transfer in Natural Waters. Academic Press, San Diego.

Morel, A., and Prieur, L., 1977. Analysis of variation in ocean color. Lymnology and Oceanography 22, 709-722.

Morichon, D., and Dailloux, D., 2006. River plume monitoring using two combined remote sensing techniques: satellite (MODIS) and video (ARGUS) images, Application to the Adour river plume (France). Proceeding of the 30th International Conference on Coastal Engineering, San Diego, 2095-2105.

Ohde, T., Siegel, H., 2003. Derivation of immersion factors for the hyperspectral TriOS radiance sensor. Journal of Optics A: Pure Applied Optics 5 (3), L12-L14.

Ouillon, S., Forget Ph., Froidefond J.M., Naudin, J.J., 1997. Estimating suspended matter concentrations from SPOT data and from field measurements in the Rhône River plume. Marine Technology Society Journal 31, 15-20.

Point, D., Bareille, G., Amouroux, D., Etcheber, H., Donard, O.F.X., 2007. Reactivity, interactions and transport of trace elements, organic carbon and particulate material in a mountain range river system (Adour River, France). Journal of Environmental monitoring 9, 
157-167).

Pope, R.M., and Fry, E.S., 1997. Absorption spectrum (380 - 700 nm) of pure water. II. Integrating cavity measurement. Applied Optics 36, 8710-8723.

R Development Core Team, 2007. An Introduction to R, Notes on R: A Programming Environment for Data Analysis and Graphics, Version 2.6.0.

Smith, R.C., and Baker, A., 1981. Optical properties of the clearest natural waters (200-800 nm). Applied Optics 20, 177-184.

Stoichev, T.D., Amouroux, D., Wasserman, J.C., Point, D., Diego, A., Bareille, G., Donard. O.F.X., 2004. Dynamics of mercury species in surface sediments of a macrotidal estuarinecoastal system (Adour river, Bay of Biscay). Estuarine, Coastal and Shelf Science 59 (3), $511-521$.

Tukey, J.W., 1977. Exploratory data analysis. Reading, Mass.: Addison Wesley.

Twardowski, M.S., Boss, E., Macdonald, J.B., Pegau, W.S., Barnard, A.H., Zaneveld, J.R.V., 2001. A model for estimating bulk refractive index from the optical backscattering ratio and the implications for understanding particle composition in case I and case II waters. Journal Geophysical Research 106 (14), 129-142.

Ulloa, O.S., Sathyendranath S., Platt, T.,1994. Effect of the particle size distribution on the backscattering ratio in seawater. Applied Optics 33, 7070-7077. 
Vermote, E.F., Tanre, D., Deuze, J.L., Herman, M., \& Morcrette, J.J., 1997. Second

Simulation of Satellite Signal in the Solar Spectrum, 6S. User Guide Version 2.

Vermote E. F., Vermeulen, A., 1999. Atmospheric correction algorithm: spectral reflectances (MOD09). Version 4.0, MODIS, Algorithm Technical Background Document.

Vermote E.F., El Saleous N., Justice C., 2002. Atmospheric correction of the MODIS data in the visible to middle infrared: First results. Remote Sensing Of Environment 83 (1-2), 97 111.

Veyssy, E., 1998. Transfert de Carbone organique, d'Azote et de Phosphore des bassins versants aux estuaires de la Gironde et de l'Adour (Sud-Ouest de la France). PhD thesis no. 1789, Sciences, Univ. Bordeaux I, France, 281 pp.

Villate, F., Franco, J., Ruiz, A., Orive, E., 1989. Caracterización geomorfológica e hidrológica de cinco sistemas estuáricos del País Vasco (1), Kobie 18. 157-170.

\begin{abstract}
Woodruff, D. L., Stumpf, R. P., Scope, J. A., Paerl. H. W., 1999. Remote estimation of water clarity in optically complex estuarine waters. Remote Sensing of Environment 68, $41_{-}$
\end{abstract}

52. 


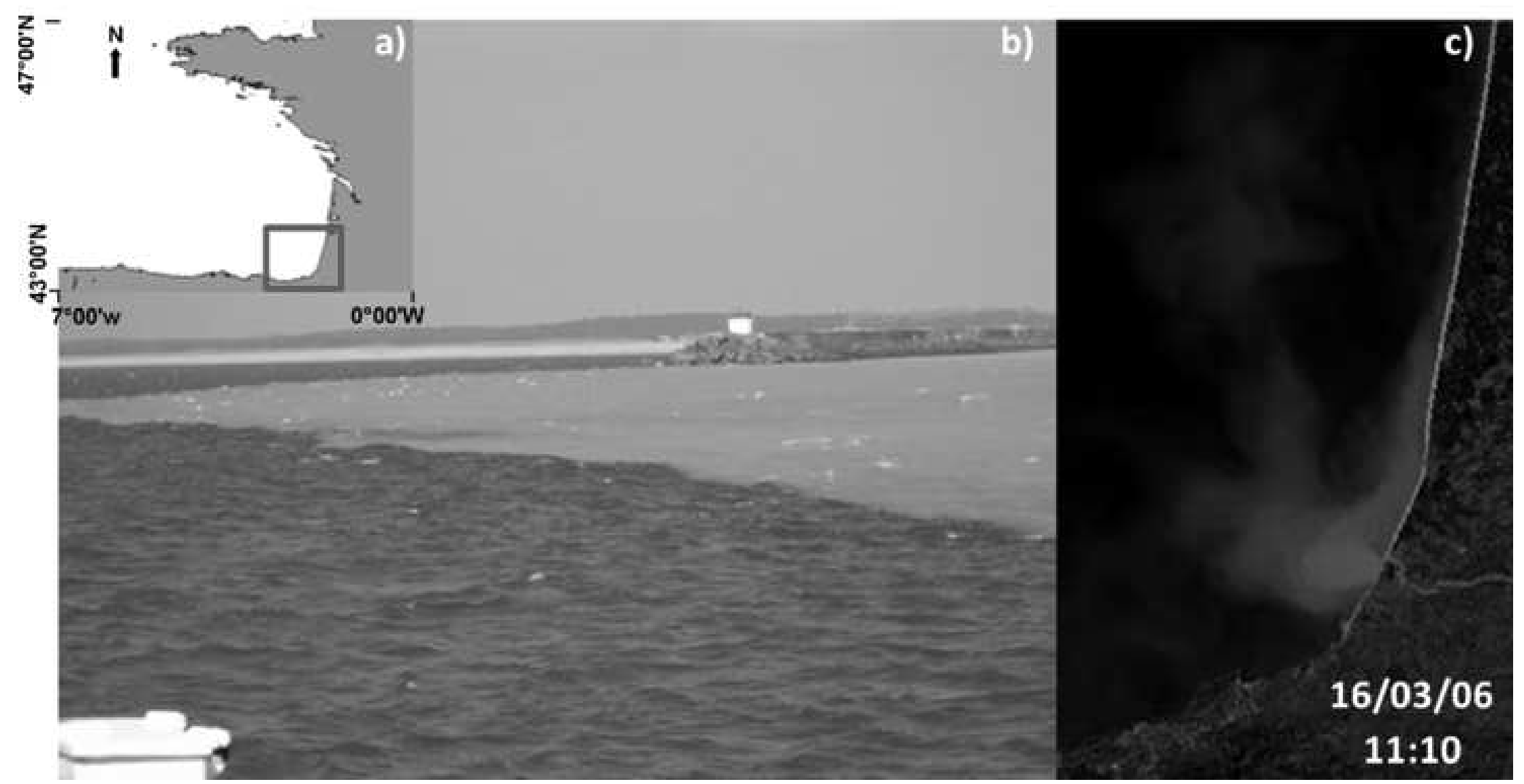



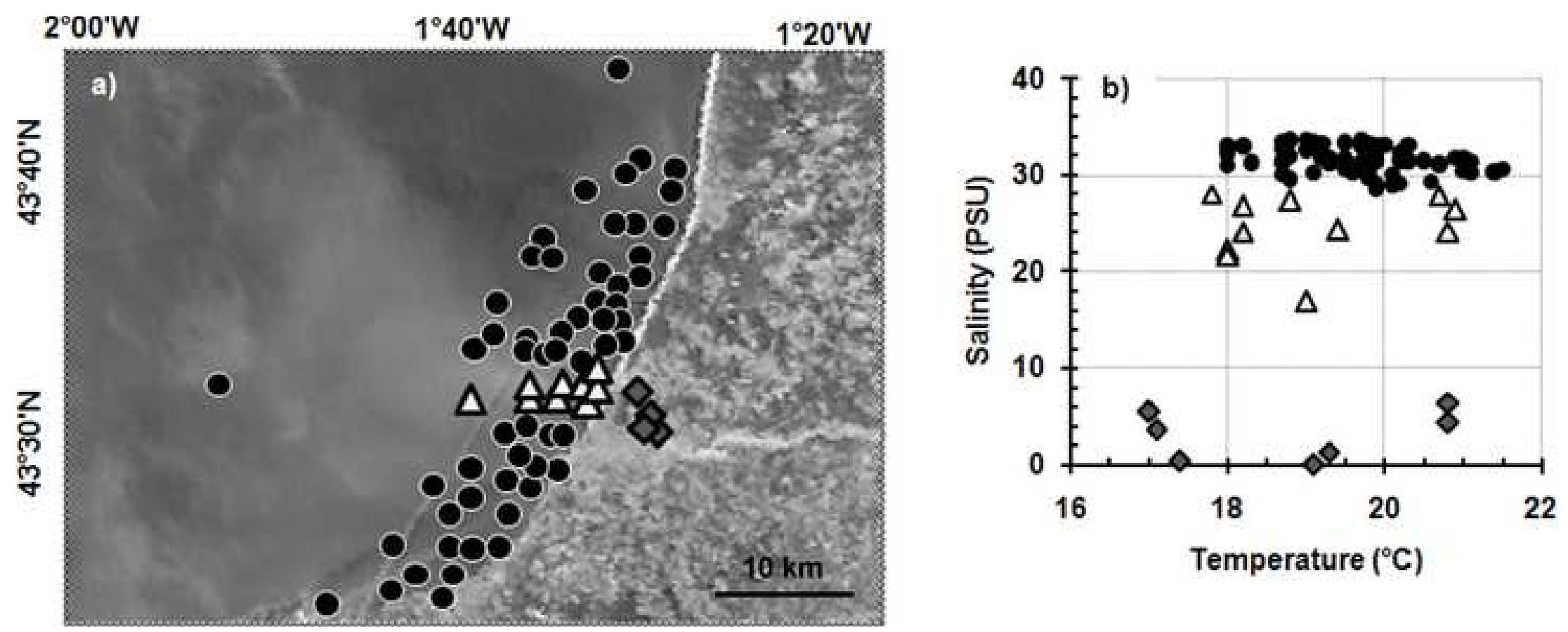

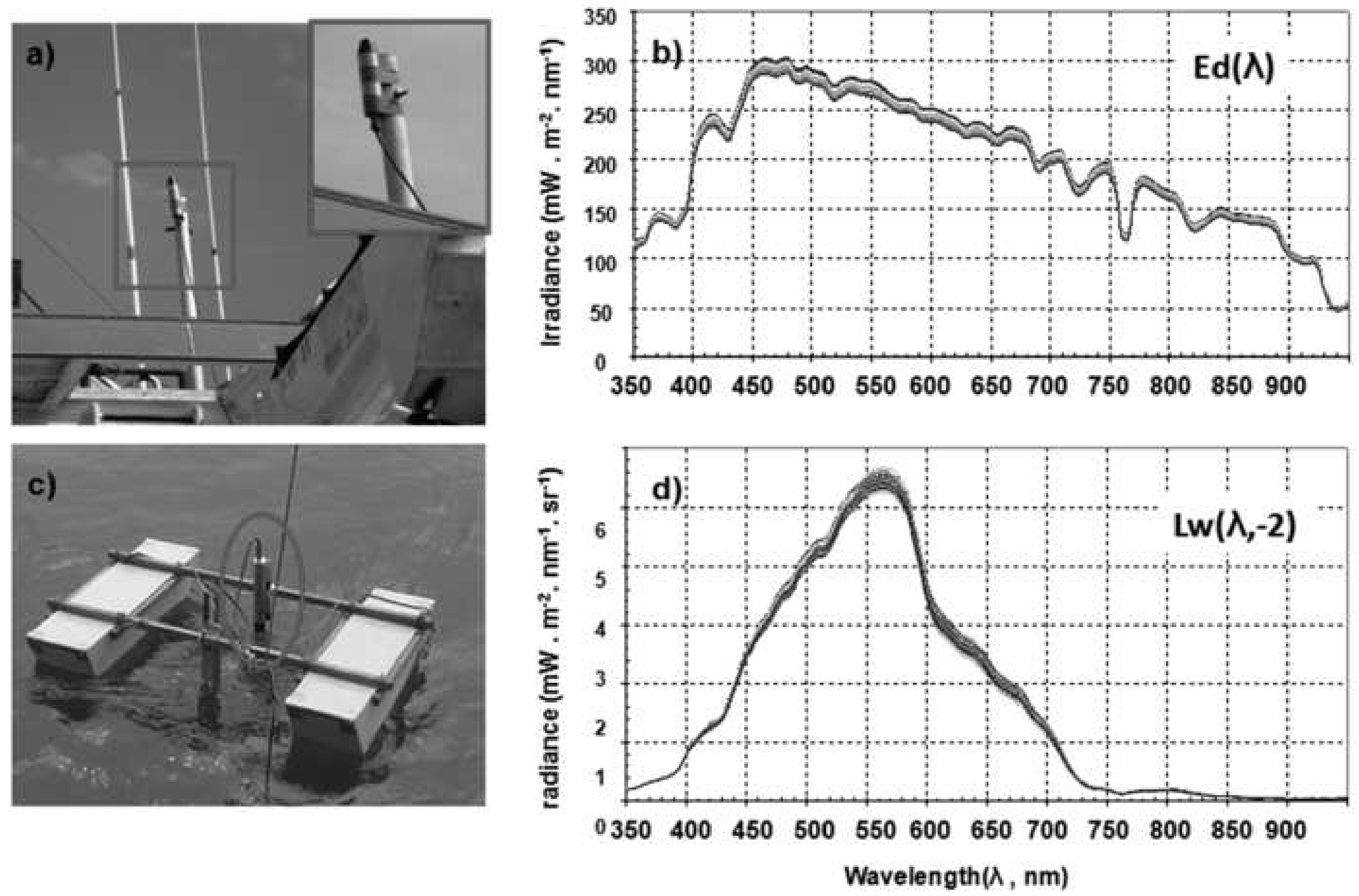


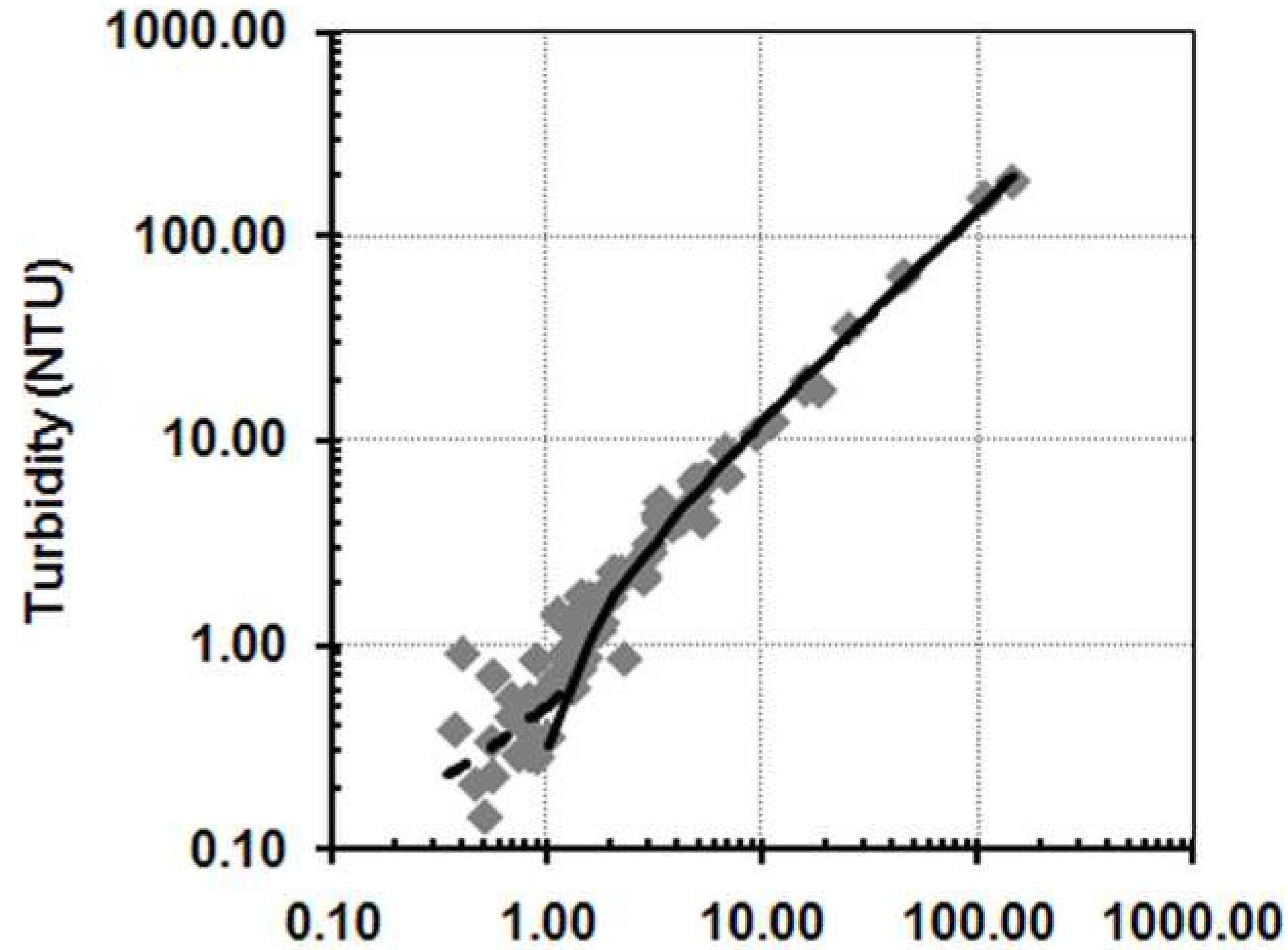

$\operatorname{TSMc}\left(\mathrm{mg} . \mathrm{I}^{-1}\right)$ 


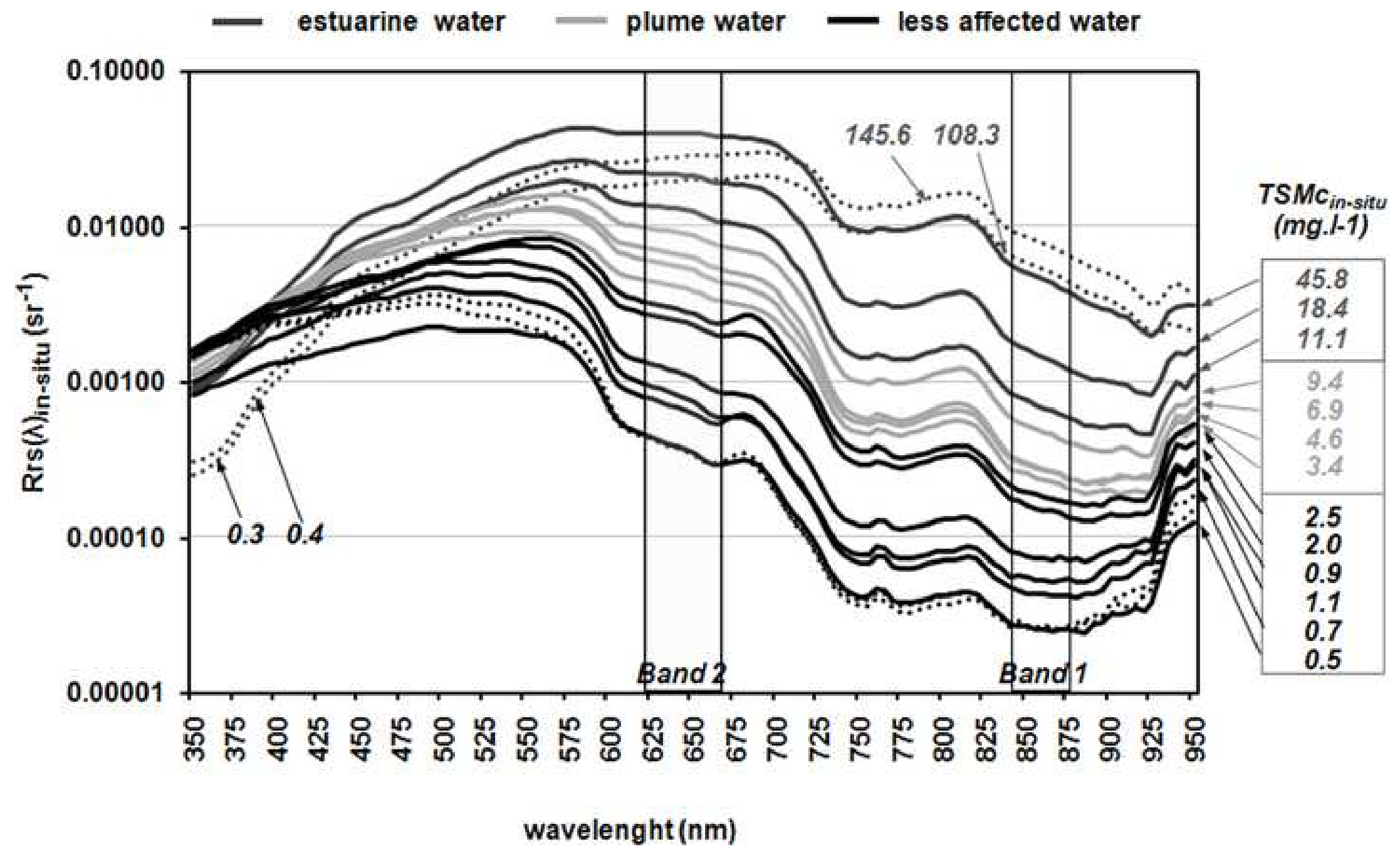



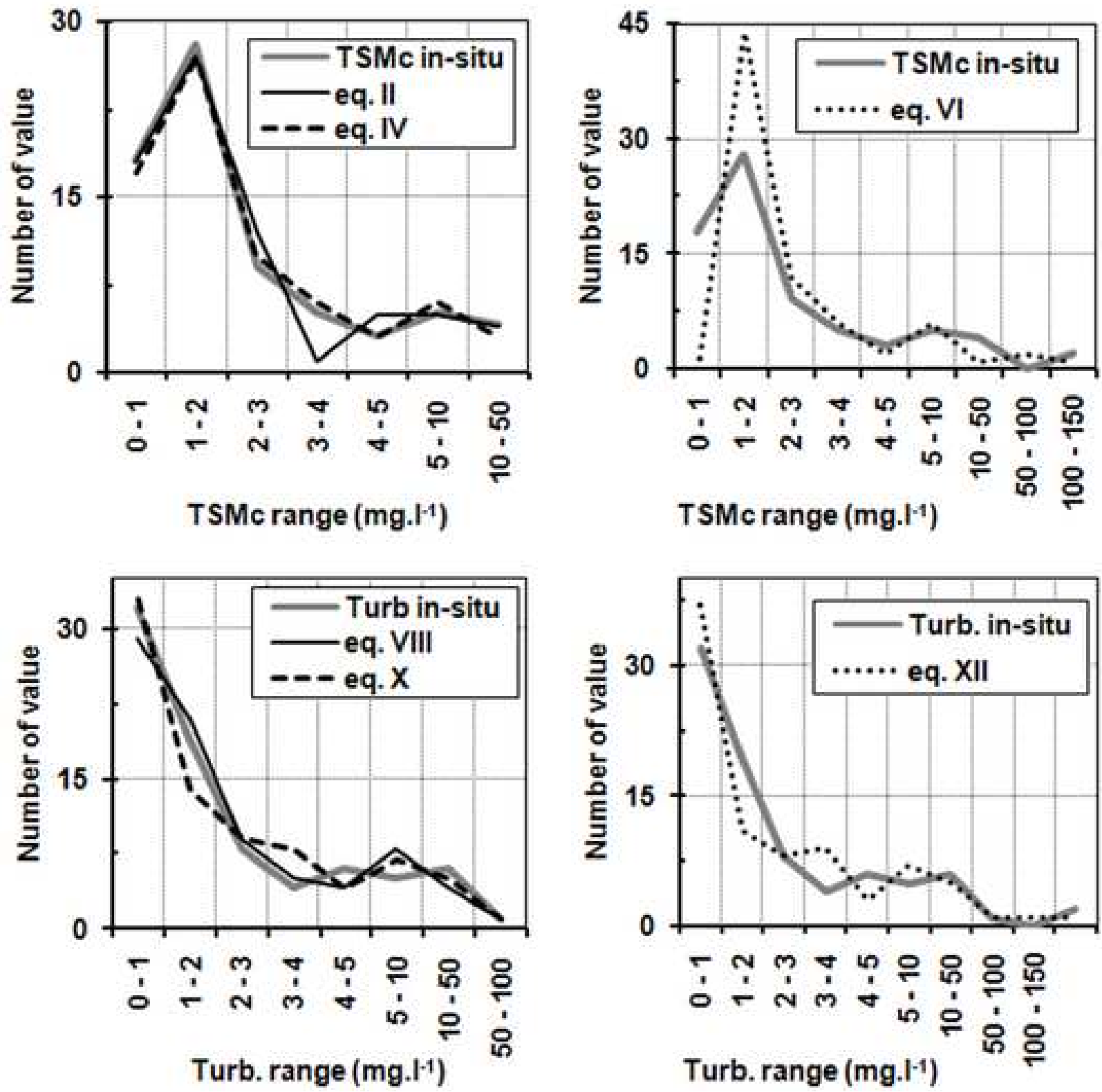

Turb. range (mg. $\mathrm{l}^{-1}$ ) Turb. range (mg. $\left.\left.\right|^{-1}\right)$ 

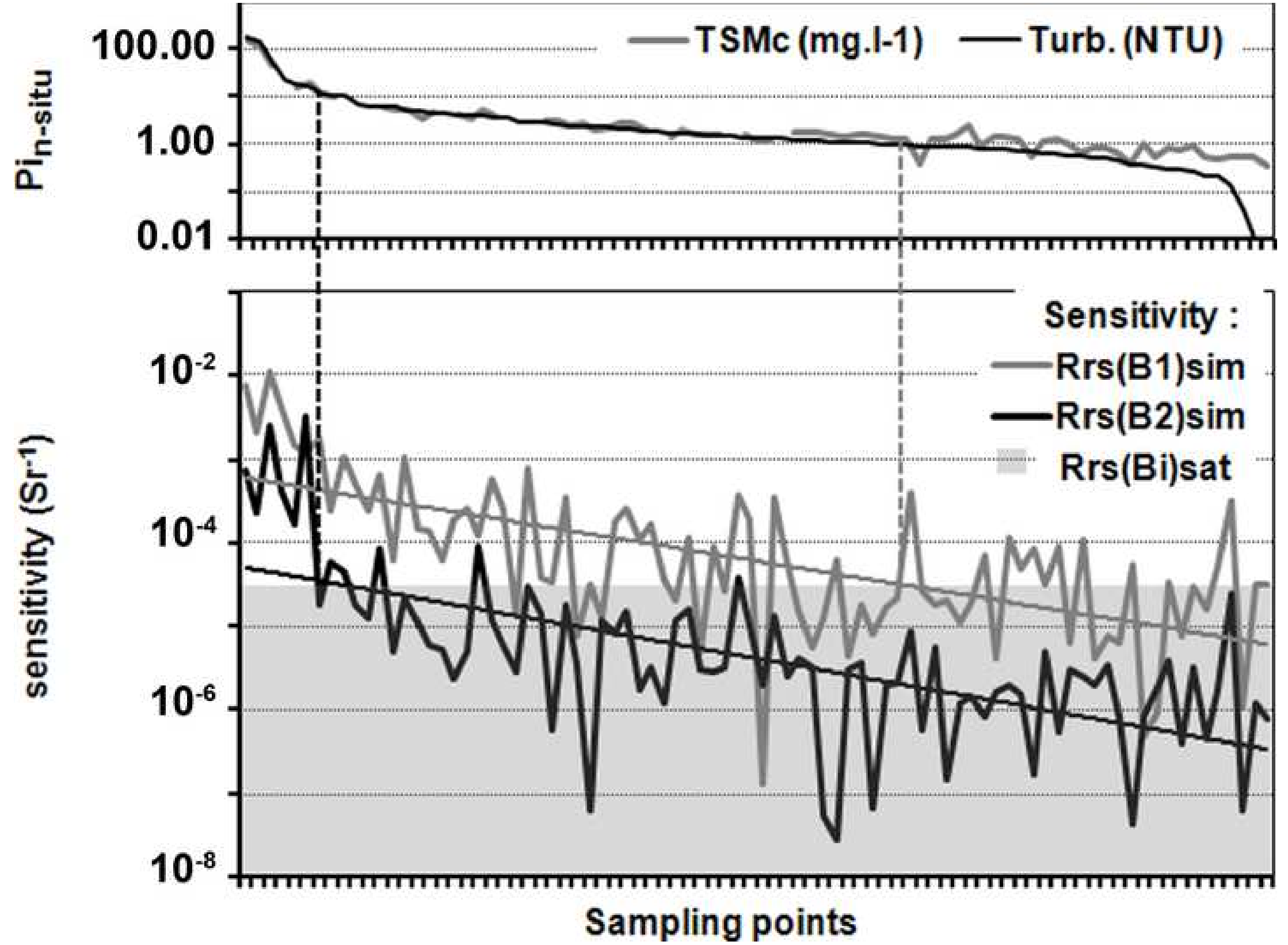


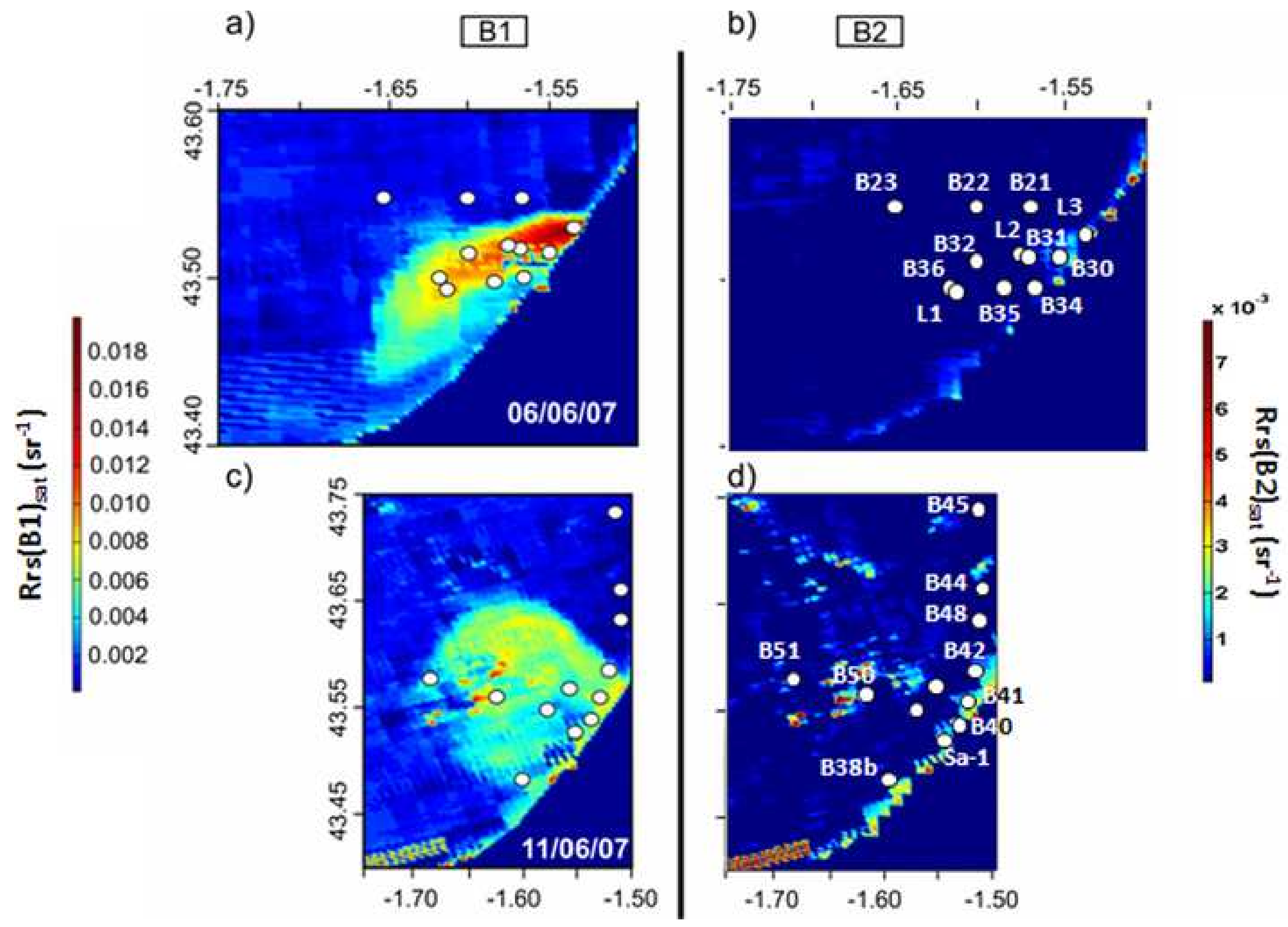




\section{6/06/07}
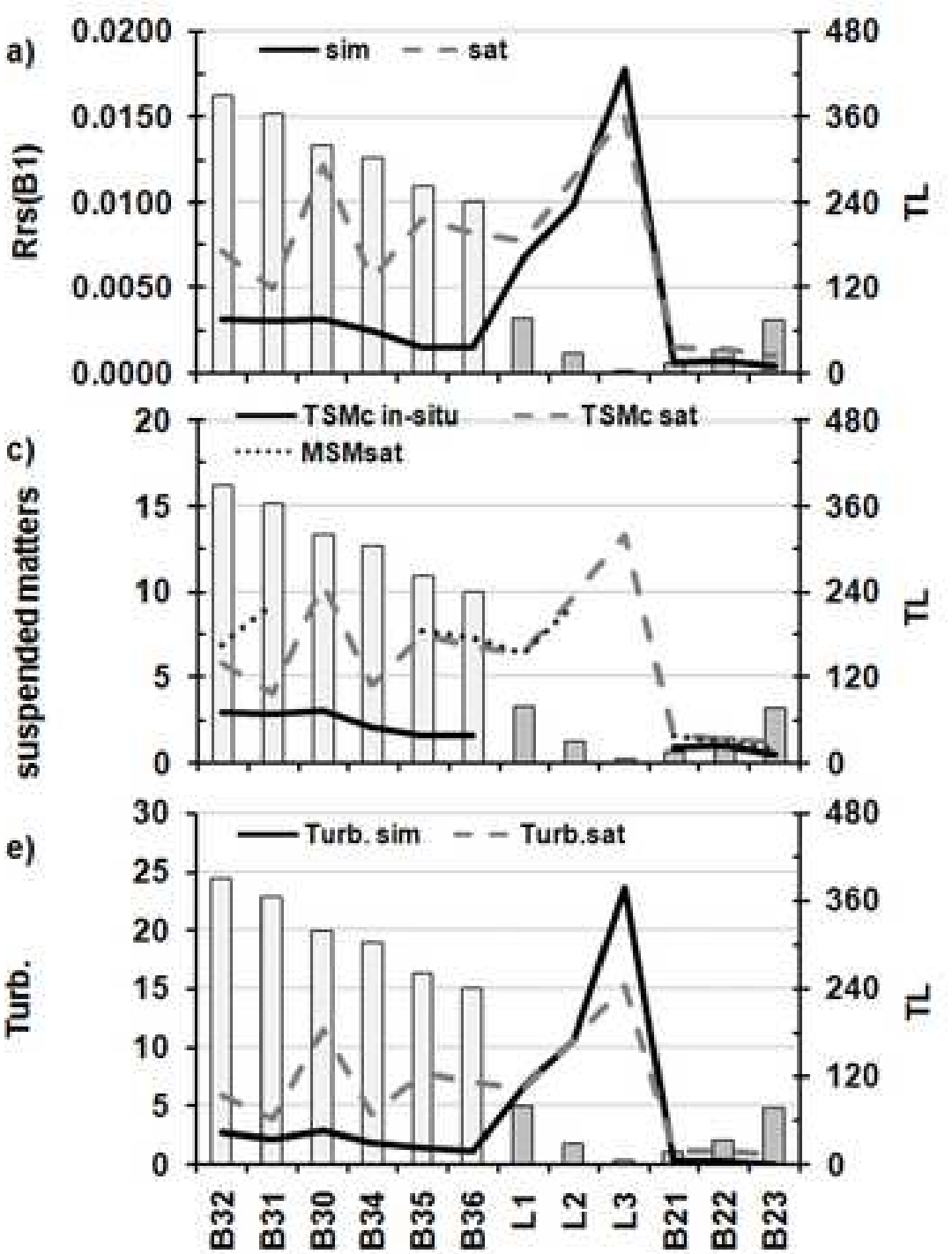

11/06/07
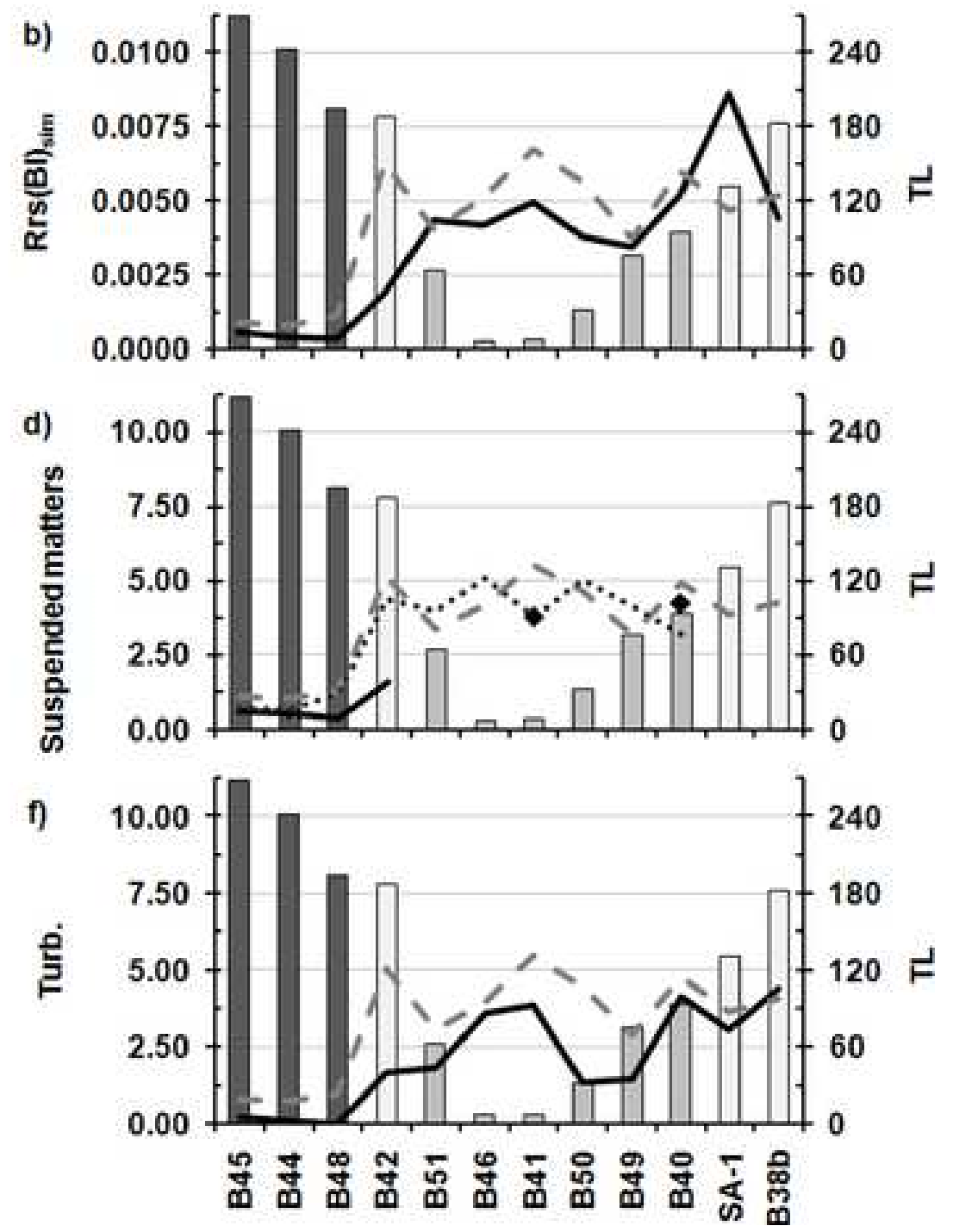

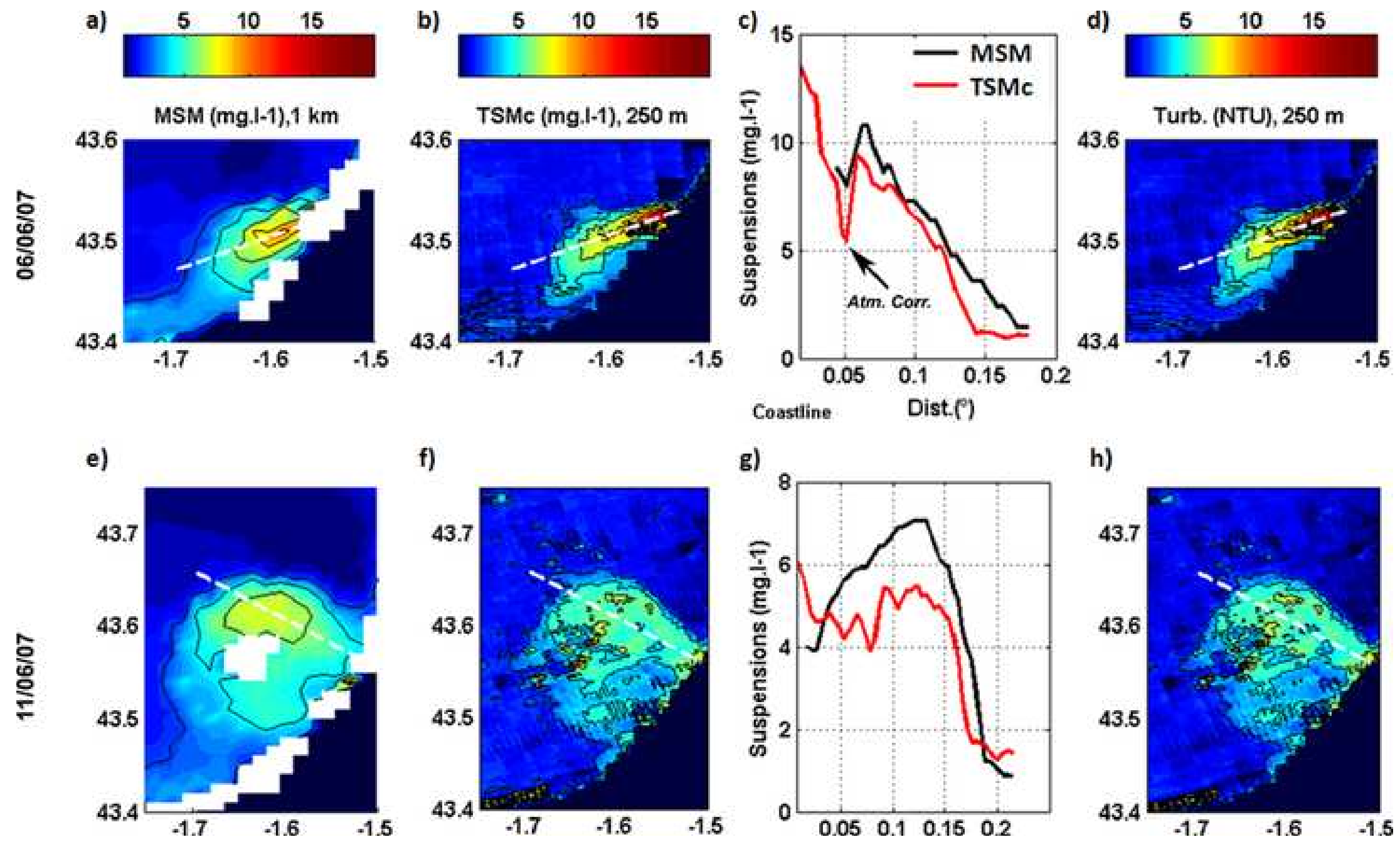
Figure

Click here to download high resolution image
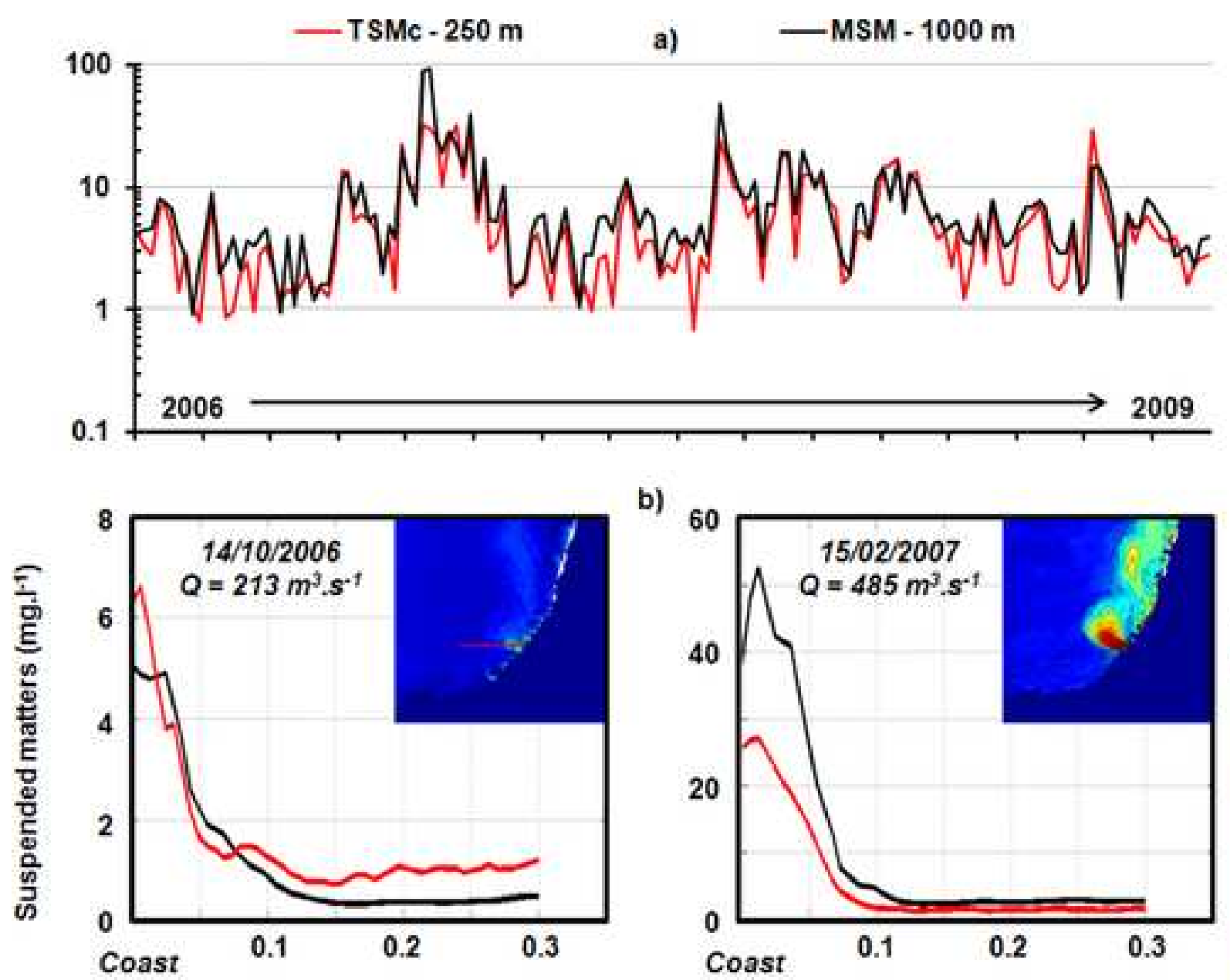

b)

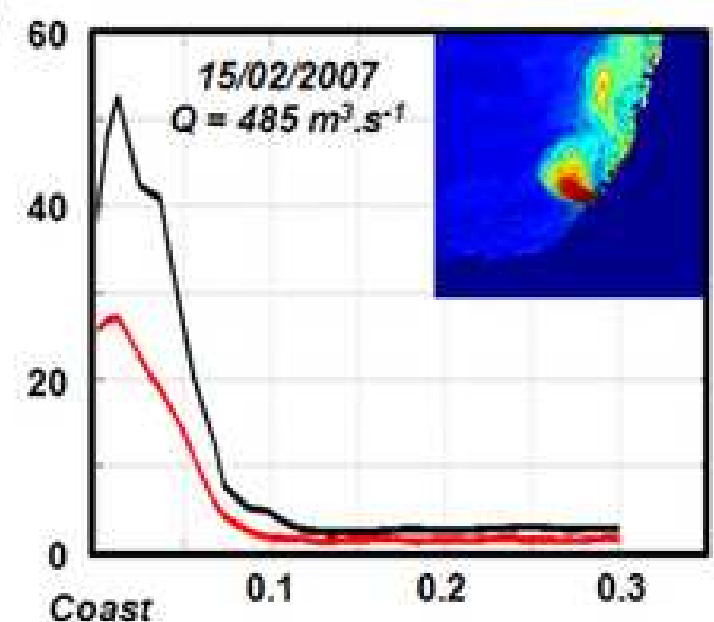

TSMc

( $\left.m g . r^{+}\right)$
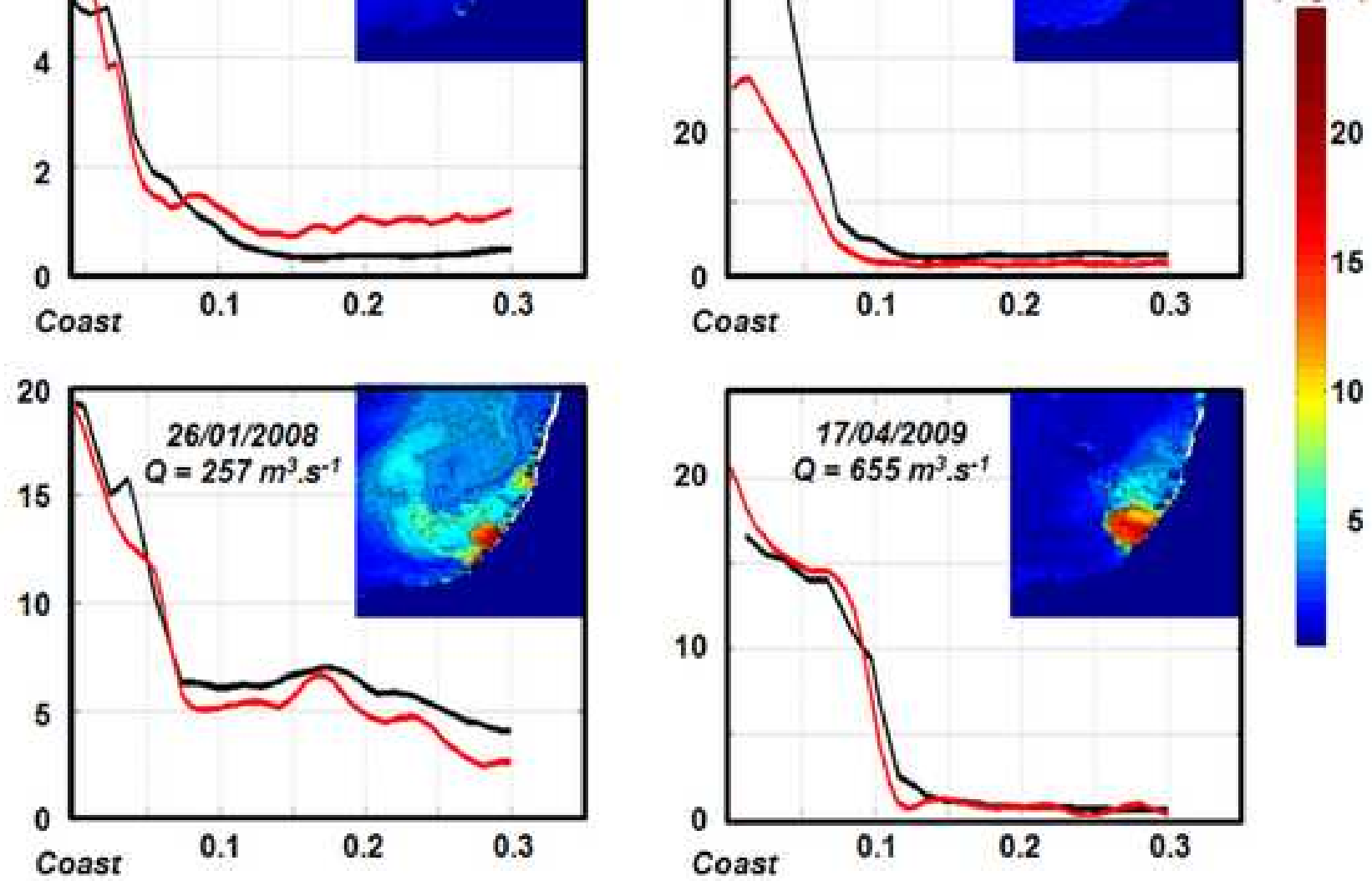

Distance from the coast $\left({ }^{\circ}\right)$ 
Figure Captions:

Fig. 1. (a) Study area in the South West of France. The Adour river plume viewed from (b) a field picture and (c) MODIS-Aqua 1-km imagery (colour composite).

Fig. 2. (a) Location of the 96 field stations during the BATEL-1 survey. (b) TemperatureSalinity diagram. Grey diamonds indicate estuarine waters; light grey triangles represent waters subject to direct inputs of freshwater runoff ("plume waters") and black circles symbolize seawaters less or not affected by the influence of the Adour plume ("less affected waters").

Fig. 3. In-situ radiometric measurements used to derive the remote sensing reflectance signal. (a) Irradiance sensor and (b) typical downwelling irradiance spectra. (c) Radiance sensor and (d) typical upwelling radiance spectra.

Fig. 4. Scatter plot and regression line for TSMc $>1 \mathrm{mg} . \mathrm{l}^{-1}$ (black line) and TSMc $<1 \mathrm{mg} . \mathrm{l}^{-1}$ (black dashed line).

Fig. 5. Sample results of $17 \operatorname{Rrs}(\lambda)_{\text {in-situ }}$ representative spectra recorded during the survey BATEL-1 for the three types of temperature-salinity water masses determined : estuarine waters (in dark grey), plume waters (in light grey) and less affected waters (in black). The corresponding $\mathrm{TSMc}_{\text {in-situ }}\left(\mathrm{mg} . \mathrm{l}^{-1}\right)$ for each sampling station is indicated on the right of the figure. Spectra corresponding to TSMcin-situ lower than $0.5 \mathrm{mg} . \mathrm{l}^{-1}$ and higher than $50 \mathrm{mg} . \mathrm{l}^{-1}$ are represented with dotted lines. $\mathrm{TSMc}_{\mathrm{in} \text {-situ }}$ corresponding to these spectra are indicated on curves. The bandwidth of Modis-Aqua band 1 and band 2 are underlined with black rectangles. The y-axis is presented with logarithmic scale.

Fig. 6. Relative Frequency Distribution plot (RFD) of polynomial models (Equations II, IV, VI, VIII, X and XII, black lines) and in-situ measurements (grey line). Top: TSMc (mg. ${ }^{-1}$ ), bottom: turbidity (NTU).

Fig. 7. $\operatorname{Rrs}(\mathrm{Bi})_{\text {sim }}$ and $\operatorname{Rrs}(\mathrm{Bi})$ sat sensitivity (equation 10) following Turb.in-situ $(\mathrm{NTU}$ ) decrease. Exponential regression lines are indicated with a grey line for band 1 and a black line for band 2 . 
Fig. 8. Synoptic maps of Rrs(Bi) $)_{\text {sat }}$ derived from MODIS-250 surface reflectance data on the $6^{\text {th }}$ of June $(a, b)$ and $11^{\text {th }}$ of June $(b, c)$. B1 and B2 indicate the bands 1 and 2, respectively. The field stations sampled on these days are indicated on maps (b) and (d).

Fig. 9. Comparisons between in-situ and satellite measurements on the $6^{\text {th }}$ of June (left) and the $11^{\text {th }}$ of June (right). From top to bottom: $(\mathrm{a}, \mathrm{b}) \operatorname{Rrs}(\mathrm{B} 1)_{\mathrm{sim}}$ and $\operatorname{Rrs}(\mathrm{B} 1)_{\mathrm{sat}}\left(\right.$ in $\left.^{-1}\right),(\mathrm{c}, \mathrm{d})$ : TSMc $_{\text {in-situ }}$, TSMc $_{\text {sat }}$ and MSM $_{\text {sat }}$ (in mg. ${ }^{-1}$ ), (e, f) Turb.in-situ and Turb.sat (in NTU). Time lag ( $\mathrm{TL}$, in $\mathrm{min}$ ) is indicated with grey bars (grey bars for $\mathrm{TL}<120 \mathrm{~min}$, light grey bars for TL $>$ 120 min and dark grey bars for stations outside the influence of the Adour plume).

Fig. 10. Synoptic suspended matter concentration maps derived from MODIS data on the $6^{\text {th }}$ (top) and $11^{\text {th }}$ of June (bottom). (a, e) MSM (mg. $1^{-1}$ ) from MODIS 1-km data, (b, f) TSMc $\left(\mathrm{mg} . \mathrm{l}^{-1}\right.$ ) from MODIS 250-m surface reflectance (band 1) and polynomial regression, (c, g) comparative curves between MSM 1-km (black lines) and TSMc 250-m (red lines). The plotted points follow a profile ( $\mathrm{a}, \mathrm{b}$ : white dashed line) parallel to the plume extension the $6^{\text {th }}$ of June and (e, f, white dashed line) perpendicular to the coast the $11^{\text {th }}$ of June. (d, h) Turb. from MODIS 250-m surface reflectance. The common colour scale for each $\mathrm{P}_{\text {sat }}$ is indicated on the right part of the figure. Atm. Corr. indicates pixels with problems on the atmospheric correction.

Fig. 11. Comparative curves between TSMc and MSM extracted: (a) on 159 MODIS data recorded from 2006 to 2009 at one fixed point near the estuary mouth; (b) along a profile (red line on the 14th of June TSMc map) on a selection of 4 days with different hydroclimatical conditions. Q is the river outflow (in $\mathrm{m}^{3} . \mathrm{s}^{-1}$ ). The corresponding TSMc maps obtained based on the algorithm II are in top right hand corners of the graphics. 


\begin{tabular}{|c|c|c|c|c|c|c|c|c|c|c|c|c|}
\hline \multicolumn{5}{|c|}{ Regression characteristics } & \multirow{2}{*}{$\begin{array}{c}\mathbf{a} \\
\mathbf{R}^{2}\end{array}$} & \multicolumn{4}{|c|}{ b } & \multicolumn{3}{|c|}{$\mathbf{c}$} \\
\hline Eq. & $\mathbf{y}$ & & $\mathbf{x}$ & $\begin{array}{c}\text { Regression } \\
\text { model }\end{array}$ & & $\begin{array}{c}R M S \\
(\%)\end{array}$ & $\begin{array}{c}\text { Emean,i } \\
<30 \%\end{array}$ & $\begin{array}{c}\text { Emean.i } \\
<50 \%\end{array}$ & $R^{2} j a c$ & $\begin{array}{c}R M S \\
(\%)\end{array}$ & $\begin{array}{c}\text { Emean,i } \\
<30 \%\end{array}$ & $\begin{array}{c}\text { Emean.i } \\
<50 \%\end{array}$ \\
\hline I & & & $\operatorname{Rrs}(\mathrm{B} 1)_{\operatorname{sim}}$ & Lin. & 0.952 & 74 & 47 & 71 & 0.904 & 52 & 51 & 76 \\
\hline II & & CS & $\operatorname{Rrs}(\mathrm{B} 1)_{\text {sim }}$ & Poly. & 0.974 & 61 & 75 & 88 & 0.967 & 34 & 79 & 93 \\
\hline III & TSMc & $\mathbf{S} \mathrm{S}_{\mathrm{l}}$ & $\operatorname{Rrs}(\mathrm{B} 2)_{\mathrm{sim}}$ & Lin. & 0.952 & 72 & 35 & 53 & 0.926 & 60 & 37 & 56 \\
\hline IV & $\left(\mathrm{mg.} \mathrm{l}^{-1}\right)$ & & $\operatorname{Rrs}(\mathrm{B} 2)_{\operatorname{sim}}$ & Poly. & 0.965 & 73 & 61 & 73 & 0.958 & 46 & 64 & 77 \\
\hline $\mathbf{V}$ & & Sc & $\operatorname{Rrs}(\mathrm{B} 2)_{\mathrm{sim}}$ & Lin. & 0.949 & 77 & 57 & 74 & 0.914 & 48 & 60 & 78 \\
\hline VI & & $\mathbf{S S}_{\mathbf{e}}$ & $\operatorname{Rrs}(\mathrm{B} 2)_{\operatorname{sim}}$ & Poly. & 0.963 & 61 & 71 & 89 & 0.913 & 37 & 75 & 94 \\
\hline VII & & & $\operatorname{Rrs}(\mathrm{B} 1)_{\operatorname{sim}}$ & Lin. & 0.902 & 1528 & 30 & 37 & 0.797 & 101 & 35 & 44 \\
\hline VIII & & $\mathbf{S}$ & $\operatorname{Rrs}(\mathbf{B 1})_{\text {sim }}$ & Poly. & 0.964 & 713 & 60 & 75 & 0.940 & 47 & 71 & 85 \\
\hline IX & Turb. & SSI & $\operatorname{Rrs}(\mathrm{B} 2)_{\mathrm{sim}}$ & Lin. & 0.954 & 1934 & 29 & 35 & 0.951 & 122 & 34 & 41 \\
\hline $\mathbf{X}$ & (NTU) & & $\operatorname{Rrs}(B 2)_{\operatorname{sim}}$ & Poly. & 0.955 & 171 & 49 & 72 & 0.945 & 60 & 53 & 76 \\
\hline XI & & & $\operatorname{Rrs}(B 2)_{\text {sim }}$ & Lin. & 0.943 & 593 & 54 & 69 & 0.913 & 58 & 62 & 78 \\
\hline XII & & $\mathrm{Ss}_{\mathbf{e}}$ & $\operatorname{Rrs}(B 2)_{\text {sim }}$ & Poly. & 0.953 & 378 & 54 & 73 & 0.884 & 59 & 60 & 79 \\
\hline
\end{tabular}

Table 1: Regression models between Rrs(B1) sim and "SS,", as well as between Rrs(B2) sim $_{1}$ and "SS " and "SS", respectively. (a) Coefficient of determination of each regression model, (b) statistical criteria calculated between the estimated water property (Pest) by the various regressions, and the in situ water property (Pin-situ), (c) statistical criteria without considering TSMc [Turb.] $<0.5$ mg. $1^{-1}$ [NTU]. Definition of $\mathrm{E}_{\text {mean,i }}(\%)$ and RMS (\%) are given in equation 6 and 7. Best regression models are indicated in bold. 


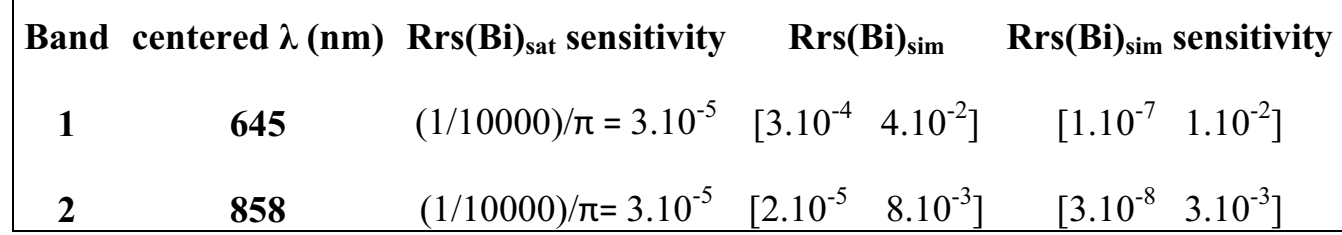

Table 2: remote sensing reflectance (in units of $\mathrm{sr}^{-1}$ ) corresponding to 1 Numeric Count (i.e. $\left.\mathrm{NC}(\mathrm{Bi})_{\text {sat }}=1\right)$ obtained from equation 8 , scale range of Rrs $(\mathrm{Bi})_{\text {sim }}$ measured in situ for the band 1 and 2 and scale range of sensitivity of $\operatorname{Rrs}(\mathrm{Bi}) \operatorname{sim}$ (equation 10 ). 
Geochemical parameters

CDOM: Coloured Dissolved Organic Matters $\left(m g . l^{-1}\right)$

MSM: Mineral Suspended Matters $\left(m g . l^{-1}\right)$

TSMc: Total Suspended Matters concentration $\left(m g . l^{-1}\right)$

Turb.: Turbidity (NTU)

With subscripts:

in-situ: measured in-situ

est : estimated using the regression models

sat: retrieved from satellite images

Optical parameters

$\operatorname{Ed}(\lambda, 0+)$ : downwelling irradiance just above the water surface at the wavelength $\lambda\left(W \cdot m^{-2} . n m^{-1}\right)$

$\mathrm{Lw}(\lambda)$ : water leaving radiance at the wavelength $\lambda\left(W \cdot \mathrm{m}^{-2} . s r^{-1} \cdot n m^{-1}\right)$

$\mathrm{NC}(\mathrm{Bi})_{\text {sat }}$ : satellite Numeric Count in the MODIS band $\mathrm{i}(\mathrm{i}=1$ or 2$)$

$\operatorname{Rrs}(\lambda)$ : Remote Sensing Reflectance at the wavelength $\lambda\left(s r^{-1}\right)$

$\operatorname{Rrs}(\lambda)_{\text {in-situ }}$ : Remote Sensing Reflectance measured in-situ

$\operatorname{Rrs}(\mathrm{Bi})_{\mathrm{in}-\text { situ }}$ : Remote sensing reflectance measured in-situ within the bandwidth of MODIS Band $\mathrm{i}(\mathrm{i}=1,2)$

$\operatorname{Rrs}(\mathrm{Bi})_{\text {sim }}$ : simulated Remote Sensing Reflectance in the MODIS band $\mathrm{i}(\mathrm{i}=1$ or 2 )

$\operatorname{Rrs}(\mathrm{Bi})_{\text {sat }}$ : satellite Remote Sensing Reflectance in the MODIS band $\mathrm{i}(\mathrm{i}=1$ or 2 )

RSR(Bi): Relative Spectral Responses of MODIS band $i(i=1$ or 2 )

Table 3: list of abbreviations and subscripts 